\title{
WestVirginiaUniversity
}

THE RESEARCH REPOSITORY @ WVU

Graduate Theses, Dissertations, and Problem Reports

2020

\section{The Immunological Response to Chronic Stress in Obese Mice}

\author{
Matthew Corey Parsley \\ West Virginia University, mcparsley@mix.wvu.edu
}

Follow this and additional works at: https://researchrepository.wvu.edu/etd

Part of the Exercise Physiology Commons

\section{Recommended Citation}

Parsley, Matthew Corey, "The Immunological Response to Chronic Stress in Obese Mice" (2020). Graduate Theses, Dissertations, and Problem Reports. 7589.

https://researchrepository.wvu.edu/etd/7589

This Thesis is protected by copyright and/or related rights. It has been brought to you by the The Research Repository @ WVU with permission from the rights-holder(s). You are free to use this Thesis in any way that is permitted by the copyright and related rights legislation that applies to your use. For other uses you must obtain permission from the rights-holder(s) directly, unless additional rights are indicated by a Creative Commons license in the record and/ or on the work itself. This Thesis has been accepted for inclusion in WVU Graduate Theses, Dissertations, and Problem Reports collection by an authorized administrator of The Research Repository @ WVU. For more information, please contact researchrepository@mail.wvu.edu. 


\title{
The Immunological Response to Chronic Stress in Obese Mice
}

\author{
Matthew Corey Parsley
}

Thesis to be submitted to the School of Medicine at West Virginia University in partial fulfillment of the requirements of the degree:

Master of Science in Exercise Physiology

Paul D. Chantler, Ph.D., Committee Chair

Randall W. Bryner, Ed.D.

I. Mark Olfert, Ph.D.

Division of Exercise Physiology

Morgantown, West Virginia

January 2020

Key Words: Obesity, chronic stress, depression, inflammation, Oxidative stress, immune, febuxostat, xanthine oxidase

Copyright 2020 Matthew Parsley 


\section{Abstract \\ The Immunological Response to Chronic Stress in Obese Mice \\ Matthew C. Parsley}

Obesity and psychological stress are major risk factors for cardiovascular disease and have a positive correlation with vascular dysfunction. This functional deficit has been linked to a pro-inflammatory milieu, exacerbated by an upregulation of proinflammatory cytokines. Febuxostat, a xanthine oxidase inhibitor, has been shown to rescue vascular impairment in these models. The purpose of this study was to examine the individual and combined effects of obesity and chronic stress on neuroimmune cell populations, and assess if febuxostat is able mediate immune alterations.

Male mice $(n=48)$ were assigned into either normal chow (lean) and high-fat diet (obese) groups. The lean animals were then separated into one of four subgroups ( $n=6 /$ group): 1) lean control, 2) lean control + febuxostat, 3) lean unpredictable chronic mild stress (UCMS), 4) lean UCMS + febuxostat. The obese counterparts were also separated into four subgroups: 1) obese control, 2) obese control + febuxostat, 3) obese UCMS, 4) obese UCMS + febuxostat. Febuxostat (50mg/L) was delivered in drinking water. Stressed mice were subjected to the UCMS paradigm which included cage tilt, no bedding, damp bedding, bath, social stress, and altered light-dark cycles for 7 hours a day, 5 days a week for 8 weeks. Coat scores were assessed to confirm the implementation of the UCMS protocol. Immediately following terminal procedures, brains were collected and processed for flow cytometry, to identify immune cell populations.

Obese animals showed a significant increase in body mass $(p<0.05)$ and UCMS groups showed a significant increase in coat scores $(p<0.05)$. Compared to lean controls, obese controls showed a significant decrease in total white blood cells, B-cells, M2 macrophages, and T-cells, and a significant increase in helper-T and cytotoxic-T cells $(p<0.05)$. Obese+UCMS showed a significant increase in total white blood cells and significant decrease in M2 macrophages $(p<0.05)$ compared to obese controls. Delivery of febuxostat did not significantly affect immune cell populations.

These data suggest that the acquisition of obesity and/or subjection to chronic stress leads to negative alterations in immune cell subsets. 


\section{Dedication}

To my pretty lady - I love you, Granny. To my friends - thank you for teaching me unconditional love. To my mom - I adore you immensely. To my special fella - thank you for taking a chance on me. To Yara, Mani, and Sally - you three are perfect. 


\section{Acknowledgements}

The Exercise Physiology program helped me to find my niche in life, serving as the interdisciplinary balance of STEM fundamentals, communal nutrition, and psychosocial factors. I knew EXPH was for me when I sat in Dr. Bryner's 386 lectures, and listened to him finally connect the dots to so many previously-learned, abstract, biological concepts. Dr. B became both an inspiration and a mentor for me, providing support any time I needed him. The undergraduate curriculum also introduced me to influential figures in the form of my passionate advisor Beth Nardella, my challenging professors Dr. McCrory, Dr. Olfert, Dr. Yakovenko, and Dr. Pistilli, and my future grad school overseers: Dr. Paul Chantler, Dr. Emily Ryan, and Mr. Danny Bonner.

My graduate teaching assistantship provided a clinical complement to my basic science research, and I was fortunate enough to be guided by Dr. Ryan and Danny. The two of them provided me with so much knowledge in leadership and gave me the chance to improve my teaching abilities. To say I am thankful for the friendship I have built with the two of them is a true understatement, as they are truly angels.

My research was completed under my mentor, Dr. Paul Chantler. My true antithesis, I am extremely grateful for PC's encouragement and constant pushing. This experience has undoubtedly been the most challenging obstacle of my life, and I am forever thankful for Paul for helping to toughen me up, while becoming a little more malleable himself. A special thanks to Emily B., Abby, Eiman, Chris, Juliana, Krista, Keshawn, Ryan, Christian, Tyler, Juilia, Justin C., Emily F., Brandon, Mary Kate, Justin M., Abundance, and every Ruby Memorial Starbucks employee who learned my name. 


\section{Abbreviations}

XO Xanthine Oxidase

ROS Reactive Oxygen Species

BMI Body Mass Index

WAT White Adipose Tissue

BAT Brown Adipose Tissue

IL- Interleukin-

TNF- $\alpha$ Tumor Necrosis Factor- $\alpha$

INF-y Interferon-y

PRR Pattern Recognition Receptors

MAMP Microbe-Associated Molecular Patterns

NK Cell Natural Killer Cell

MHC Major Histocompatibility Complex

TCR T-Cell Receptors

UCMS Unpredictable Chronic Mild Stress

DHEA Dehydroepiandrosterone 


\section{Table of Contents}

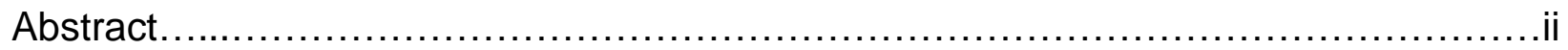

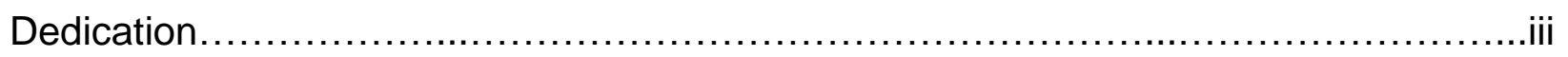

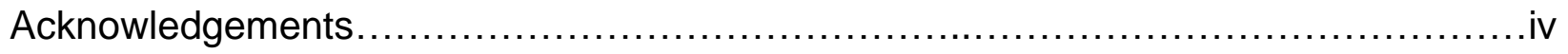

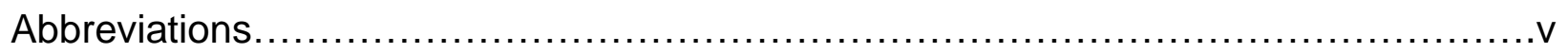

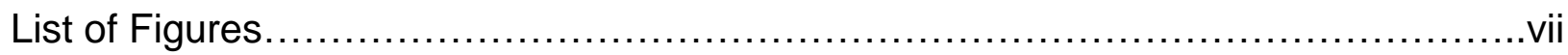

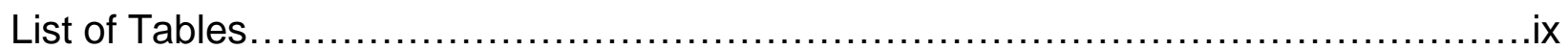

Chapter 1

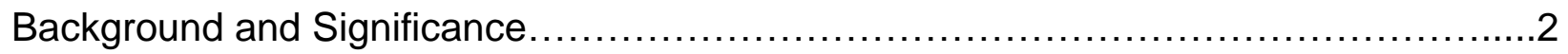

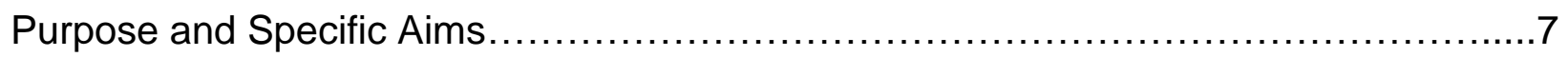

Chapter 2

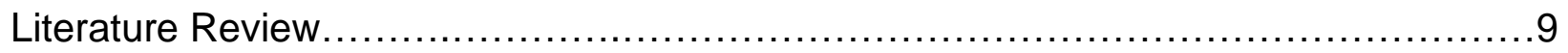

Chapter 3

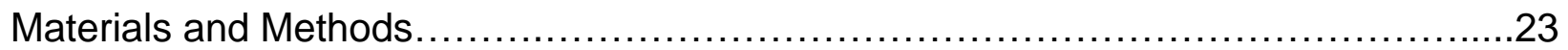

Chapter 4

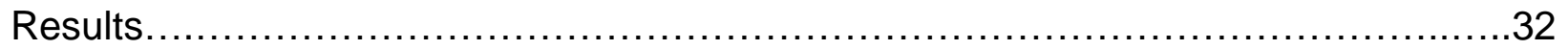

Chapter 5

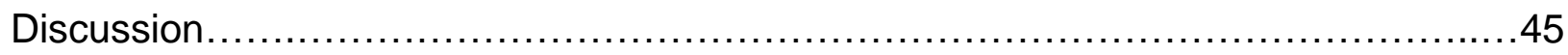

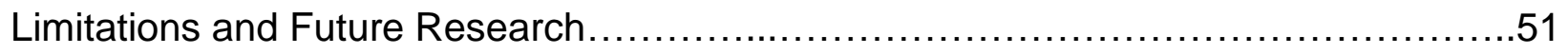

$\underline{\text { Chapter } 6}$

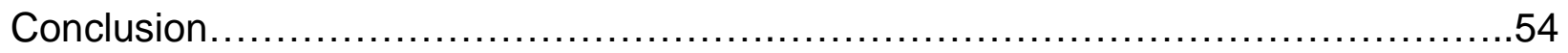






\section{List of Figures}

1 Figure 1-1 shows the prevalence of obesity among US citizens from 1972-2014. Blue line with diamond markers are adults ages 20-47, red line with box markers are ages 2-19.

2 Figure 1-2 shows an overview of inflammatory activation and subsequent effects resulting from psychosocial stress.

3 Figure 1-3 shows the reduction of molecular oxygen, forming free radicals

4 Figure 1-4 shows $A$ ) effects of oxidation of hypoxanthine to uric acid and superoxide by xanthine oxidase (XO), B) inhibition of $\mathrm{XO}$ by febuxostat.

5 Figure 2-1 presentation of antigen from Major Histocompatibility Complex region of antigen presenting cell to the unique $\mathrm{T}$-cell receptor for T-cell priming.

6 Figure 2-2 showcases the complex interplay of a multitude of systems providing feedback to attain systemic homeostasis.

7 Figure 2-3 Febuxostat causes reversible inhibition of xanthine oxidase action.

8 Figure 3-1 Stained spleen cells magnified under microscope

9 Figure 3-2 Gating strategy to determine cell populations obtained from LSRFortessa using FCS Express 6 Flow Research Edition software.

10 Figure 4-1: Percentage of white blood cells (CD45+) in lean and obese animals with febuxostat (Con+Feb) treatment. ${ }^{*} p<0.05$ vs lean control (Con). $n=4-5$ per group.

11 Figure 4-2: Percentage of A) T-cells (CD3+), B) Helper-T cells (CD4+), C) Cytotoxic$T$ cells (CD8+), and D) the CD4+ to CD8+ ratio (an indicator of inflammation) in lean and obese animals with febuxostat $(\mathrm{Con}+\mathrm{Feb})$ treatment. $\mathrm{p}<0.05$ vs lean control (Con). $n=4-5$ per group.

12 Figure 4-3: Percentage of $B$-cells $(C D 45 R+)$ in lean and obese animals with febuxostat treatment (Con+Feb). $p<0.05$ vs lean control (Con). $n=4-5$ per group.

13 Figure 4-4: Percentage of A) M1 macrophages, B) M2 macrophages, C) the M1/M2 ratio (an indicator of inflammation) in lean and obese animals with febuxostat treatment (Con+Feb). $p<0.05$ vs lean controls (Con). $n=4-5$ per group.

14 Figure 4-5: Percentage of white blood cells (CD45+) in lean and obese animals with UCMS. ${ }^{*} p<0.05$ vs obese control (Con). $n=4-5$ per group.

15 Figure 4-6: Percentage of A) T-cells (CD3+), B) Helper-T cells (CD4+), C) Cytotoxic$T$ cells $(C D 8+)$, and $D$ ) the CD4+ to CD8+ ratio (an indicator of inflammation) in lean and obese animals with UCMS. $n=4-5$ per group.

16 Figure 4-7: Percentage of B-cells (CD45R+) in lean and obese animals with UCMS. $n=4-5$ per group.

17 Figure 4-8: Percentage of A) M1 macrophages, B) M2 macrophages, C) the M1/M2 ratio (an indicator of inflammation) in lean and obese animals with UCMS. $p<0.05$ vs obese controls (Con). $n=4-5$ per group.

18 Figure 4-9: Percentage of white blood cells (CD45+) in lean and obese animals with UCMS and febuxostat treatment (UCMS+Feb). $n=4-5$ per group.

19 Figure 4-10: Percentage of A) T-cells (CD3+), B) Helper-T cells (CD4+), C) Cytotoxic$T$ cells (CD8+), and $D$ ) the CD4+ to CD8+ ratio (an indicator of inflammation) in lean and obese animals with UCMS and febuxostat treatment (UCMS+Feb). $n=4-5$ per group. 
20 Figure 4-11: Percentage of $B-c e l l s(C D 45 R+)$ in lean and obese animals with UCMS and febuxostat treatment (UCMS+Feb). $n=4-5$ per group.

21 Figure 4-12: Percentage of A) M1 macrophages, B) M2 macrophages, C) the M1/M2 ratio (an indicator of inflammation) in lean and obese animals with UCMS and febuxostat treatment (UCMS+Feb). $n=4-5$ per group. 


\section{List of Tables}

1. Table 3-1: Antibody-to-cell type pairings

2. Table 4-1: Animal Characteristics

3. Table 4-2: Coat Scores 


\section{Chapter 1}

\section{Introduction}




\subsection{Background and Significance}

Clinical obesity is an accumulation of excessive adipose tissue, and is defined as a Body Mass Index (BMI) of $30 \mathrm{~kg} / \mathrm{m}^{2}$ or higher in adults, and a $\mathrm{BMI} \geq 95^{\text {th }}$ percentile in children. ${ }^{13,16,18}$ Studies have identified that $30-40 \%$ of adults and $15-20 \%$ of children in the United States are classified as obese, with percentages increasing by 2-3 fold over the 40 years (Figure 1-1). ${ }^{1,2,13,14,17}$ Though interventions have been implemented, there have not been any substantial methodologies to deter the ongoing obesity trends; this is especially concerning due to the global prevalence of obesity. ${ }^{2,3,4}$ Obesity has been shown to have a strong correlation with additional disease states, often being a contributing factor for diabetes mellitus, cardiovascular disease, and systemic inflammation. . $^{2,5,6,7,8,9,10}$

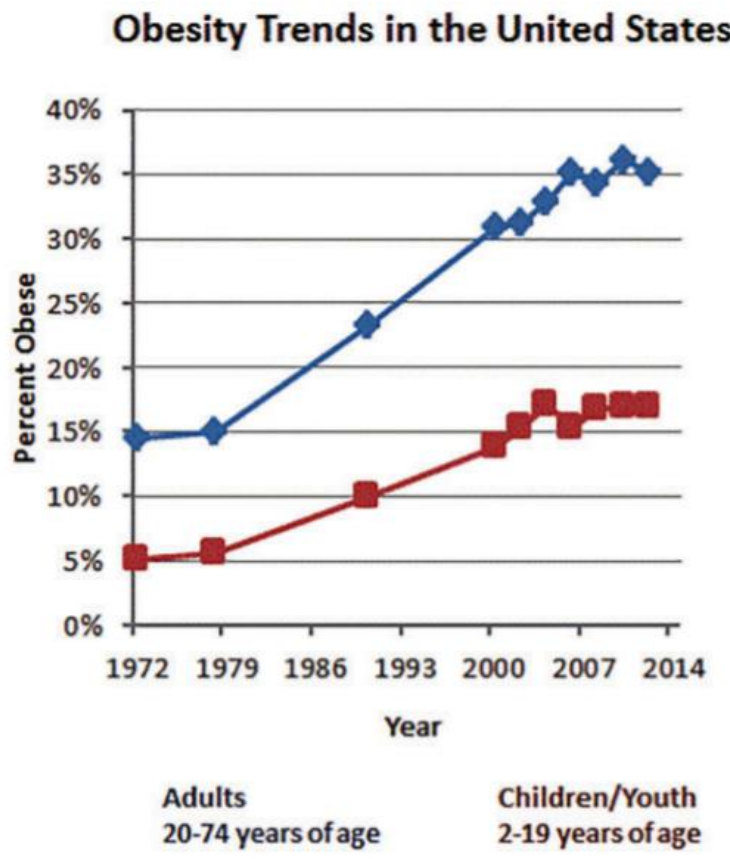

Figure 1-1 shows the prevalence of obesity among US citizens from 1972-2014. Blue line with diamond markers are adults ages $20-47$, red line with box markers are ages 2-19. ${ }^{14}$ 
A hallmark of obesity is an overaccumulation of endocrinologically-active adipose tissue, which acts as a reservoir for immune cells. ${ }^{11}$ The composition of the adipose tissue has a significant correlation with its immunological activity, with obesity correlating with disproportionate increases in white adipose tissue (WAT), and a subsequent accumulation of immune cells, including macrophages. ${ }^{20,22}$ Macrophages are a primary cell type in the body's innate immune system, acting as the primary line of defense against a foreign entity. ${ }^{19}$ The functional characteristics of the macrophages are dependent on their environment, which affects its phenotype; M1 macrophages are characterized as pro-inflammatory cells, while M2 macrophages are anti-inflammatory. ${ }^{22}$ While inflammation is an important step of the immune response, chronic activation of proinflammatory immune cells increases the production of pro-inflammatory cytokines, which are chemical messengers that, in excess, can exacerbate the potential of developing comorbidities. $^{21,22}$

Similarly, to obesity, psychological disorders have been recognized as a risk factor for the propagation of other diseases. According to the National Institute of Mental Health, more than 17 million adults have suffered a depressive episode, and approximately 10$20 \%$ of adults in the U.S. are expected to suffer from major depressive disorder, a form of chronic stress, at some point in their lives. ${ }^{23,24}$ Chronic stress increases neuroendocrine activation, with stress hormones like cortisol being activated in synergy with the sympathetic nervous system (Figure 1-2). ${ }^{25}$ As this occurs, systemic inflammation manifests, with activated immune cells secreting pro-inflammatory cytokines including interleukin-6 (IL-6), tumor necrosis factor- $\alpha$ (TNF- $\alpha$ ), and interferon- $\gamma($ INF- $-\gamma){ }^{25,26,28}$ The chronic release of cytokines results in a positive feedback loop; continued inflammation 
decreases immune cells' sensitivity to glucocorticoids, which would normally deactivate the inflammatory response. ${ }^{27,29}$ The persisting inflammation caused by chronic stress or obesity has negative systemic implications, including potential damage to the brain and catalyzing vascular dysfunction. Overaccumulation of immune cells increases the development of arterial plaques; combined with TNF- $\alpha$ acting as an antagonist of nitric oxide (NO) production, a potent vasodilator, the potential for vascular damage is greatly compounded. $28,36,37$ Persistence of stress leads to subsequent insulin resistance, a decreased sensitivity to insulin which results in mitochondrial dysfunction, oxidative stress, and an exacerbation of inflammation. ${ }^{85}$ This pro-inflammatory milieu increases the long-term potential of developing cardiovascular disease or having a stroke..$^{38,39}$

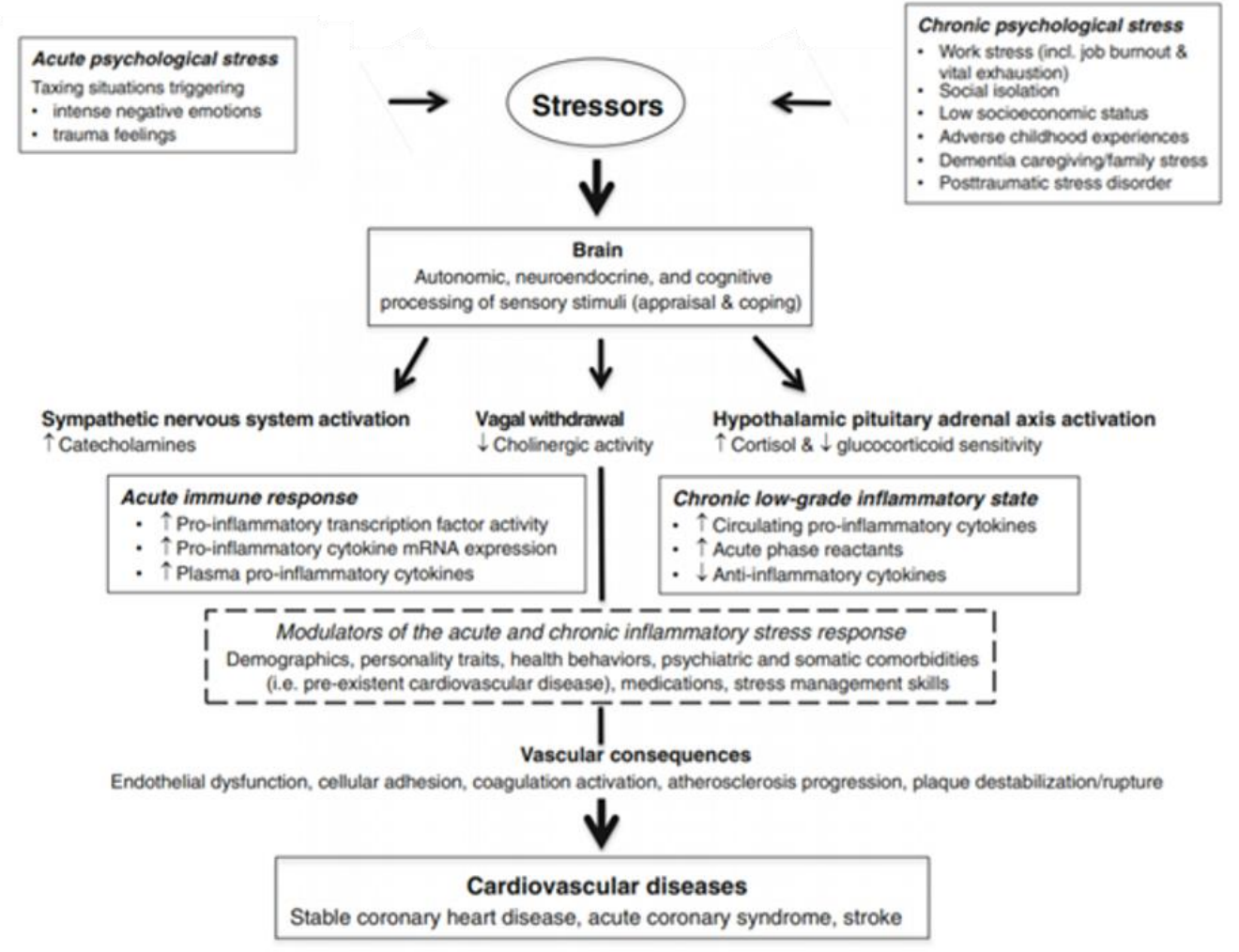

Figure 1-2 shows an overview of inflammatory activation and subsequent effects resulting from psychosocial stress. ${ }^{25}$ 
A mutual consequence of chronic stress and obesity is a surge of oxidative stress, resulting from the increase in pro-inflammatory cytokines. ${ }^{30}$ Oxidative stress is the result of free radicals or reactive oxygen species (ROS) accumulating in the system, and are distinguished by their unpaired electrons (Figure 1-3). ${ }^{15}$ Normally scavenged by antioxidants, an increase in ROS can lead to intermolecular reactions, ultimately causing tissue and vascular damage..$^{15,31}$

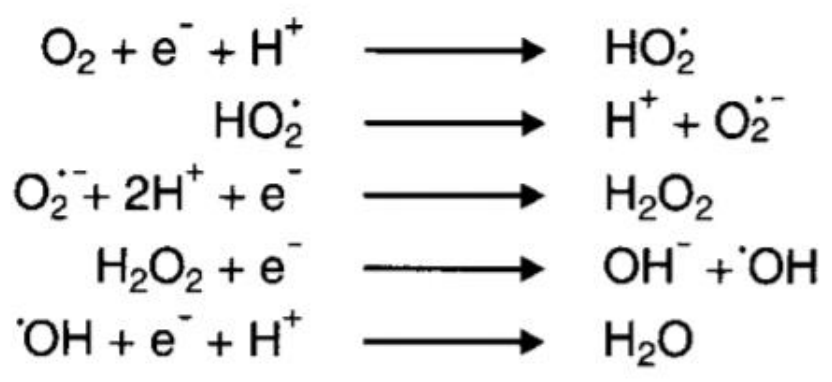

$\mathrm{HO}_{2}^{*}=$ hydroperoxyl radical

$\mathrm{O}_{2}^{--}=$superoxide radical

$\mathrm{H}_{2} \mathrm{O}_{2}=$ hydrogen peroxide

$\cdot \mathrm{OH}=$ hydroxyl radical

Figure 1-3 shows the reduction of molecular oxygen, forming free radicals. ${ }^{15}$

Along with uric acid, ROS are a major byproduct in the catalysis of xanthine, a process mediated by xanthine oxidase $(\mathrm{XO}) .^{32}$ This pathway is overstimulated in obese models, leading to an influx of ROS production and subsequent tissue damage..$^{31,32}$ Independent of obesity, xanthine+xanthine oxidase supplementation has been utilized as a model for oxidative stress induction; this model has been shown to lead to an increase in anxious and depressive symptoms, as well as insulin resistance..$^{33}$ Effects of $\mathrm{XO}$ have been shown to be attenuated by pharmacological intervention of febuxostat, which acts as an inhibitor of uric acid metabolism by exerting opposing action to the catalyst, $\mathrm{XO} .{ }^{35}$ 
Febuxostat, in turn, has been shown to inhibit ROS production and improve endothelial function (Figure 1-4). ${ }^{34,130}$

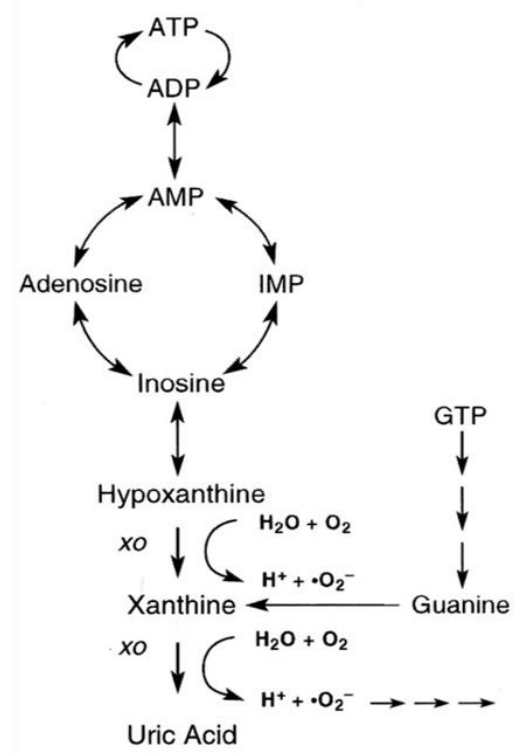

A
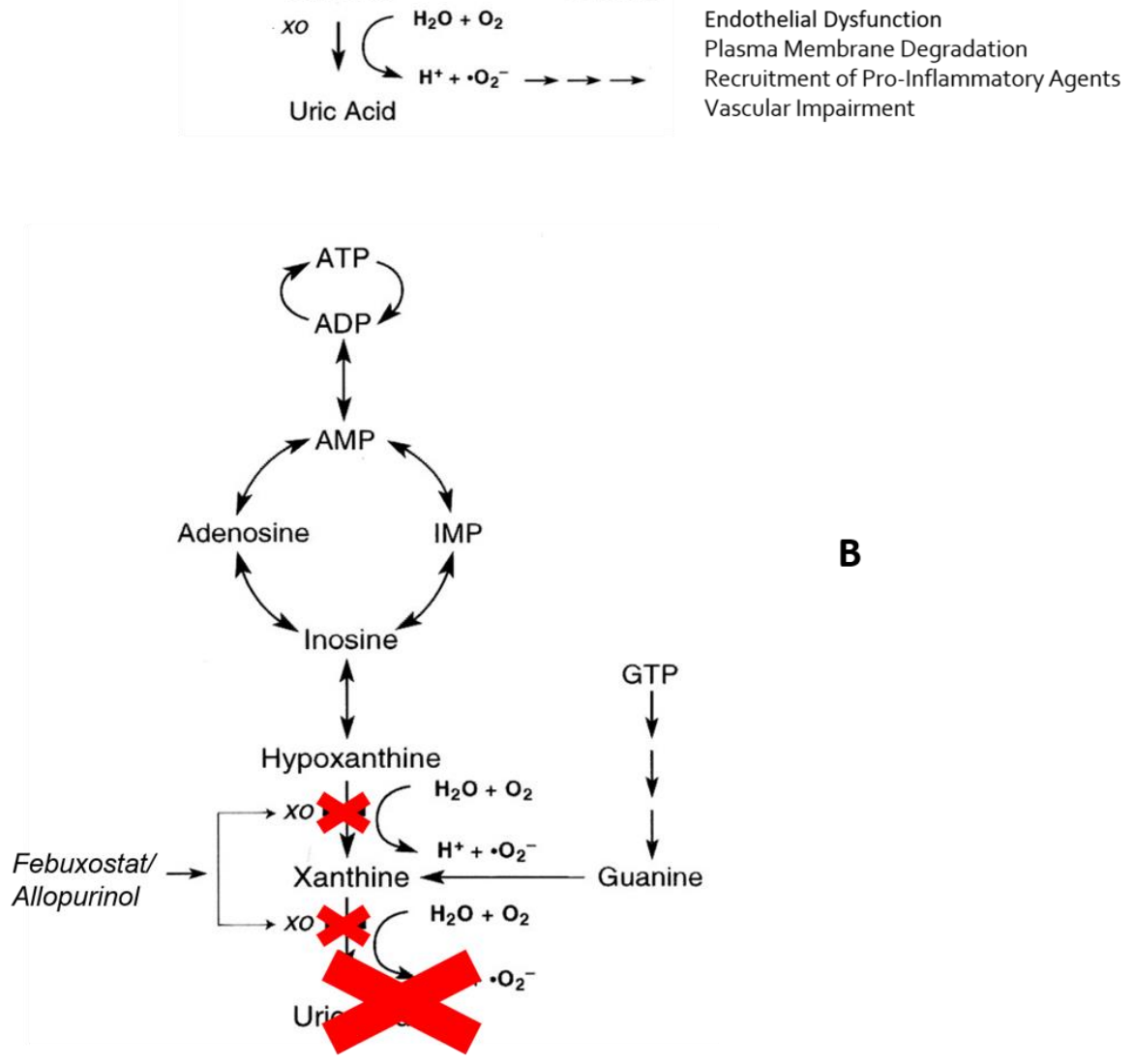

B

Figure 1-4 shows $A$ ) effects of oxidation of hypoxanthine to uric acid and superoxide by xanthine oxidase (XO), B) inhibition of $\mathrm{XO}$ by febuxostat. ${ }^{130}$ 


\subsection{Purpose and Specific Aims}

The purpose of this study was to examine the individual and combined effects obesity and chronic stress have on the prevalence of immune cell populations. This was done to better understand the pathways leading to vascular dysfunction. Further, the study used the chronic delivery of febuxostat in drinking water, to combat the potential dysfunction associated with the production of superoxides by way of the xanthine oxidase pathway. This was implemented to assess if febuxostat has the ability to attenuate increases in the pro-inflammatory milieu observed with the delivery of stressors. We hypothesized that obesity, chronic stress, and a combination of obesity and chronic stress would lead to an increase in pro-inflammatory immune cells and subsequent release of pro-inflammatory cytokines. Additionally, we hypothesized that the animals given febuxostat would have a decrease in pro-inflammatory agents, and an increase in anti-inflammatory cells.

Specific Aim 1: To determine the effects of chronic febuxostat treatment on brain immune cell populations in lean and obese mice.

Hypothesis: The chronic delivery of febuxostat will decrease the exacerbated proinflammatory milieu that is seen in obese models, giving a more anti-inflammatory phenotype, similar to lean controls.

Specific Aim 2: To determine the effects of chronic stress on the brain's immune cell populations in lean and obese mice.

Hypothesis 2: Eight weeks of unpredictable chronic mild stress will increase the prevalence of pro-inflammatory cells, including $\mathrm{CD}^{+}{ }^{+} \mathrm{T}$-cells and the $\mathrm{M} 1$ macrophage phenotype and obesity will exacerbate these effects. 
Specific Aim 3: To determine the effects of chronic febuxostat treatment on brain immune cell populations in lean and obese mice that have been chronically stressed.

Hypothesis 3.1: Chronic delivery of febuxostat on lean animals that have been chronically stressed will attenuate the shift in the pro-inflammatory milieu, thereby increasing the ratio of $\mathrm{CD}^{+}$to $\mathrm{CD}^{+}$cells and decreasing the $\mathrm{M} 1$ to $\mathrm{M} 2$ macrophage ratio.

Hypothesis 3.2: The chronic delivery of febuxostat will reverse the proinflammatory state, resulting from a combination of obesity and chronic psychological stress. This would cause an anti-inflammatory shift, overall, leading to an increase in anti-inflammatory cells such as $\mathrm{CD}^{+}{ }^{+} \mathrm{T}$-cells and the M2 macrophage, with an additional decrease in the pro-inflammatory CD8 ${ }^{+} \mathrm{T}$-cells and the M1 phenotype. 


\section{Chapter 2}

\section{Literature Review}




\subsection{The Immune System}

The immune system is the body's intricate defense used to ward off potential pathogens; entities that have been internalized and are recognized as "foreign". When a pathogen is detected, the immune system utilizes a diverse array of cell types and molecular pathways to eliminate the invasive target, thereby reducing harm to the host. The immune system is generally divided into two branches: the innate immune system and the adaptive immune system.

\subsubsection{The Innate Immune System}

When a pathogen protrudes beyond the physical barriers of the skin and mucosa, the cellular component of the innate immune system coordinates a rapid response.${ }^{41}$ Lead by monocyte-originating macrophages, the immune cells serve a dual role in the inflammatory response: phagocytosis of foreign invaders and cytokine release. ${ }^{41,42,43}$ Phagocytosis is the engulfment of the invader, with intracellular enzymes nullifying the pathogen, allowing for subsequent antigen presentation to the adaptive immune system. ${ }^{42}$ Macrophages utilize toll-like receptors and scavenger receptors, collectively referred to as pattern recognition receptors (PRR), which allow them to recognize the microbe-associated molecular patterns (MAMP) of pathogens, leading to engulfment and phagocytosis..$^{42,43,44,48}$

The immunological hallmark of the Central Nervous System is the presence of microglia: cells that serve as the brain's resident macrophage population, that are housed on the internal side of the blood brain barrier. ${ }^{49,50}$ Like peripheral macrophages, microglia exhibit both the pro-inflammatory M1 phenotype and the anti-inflammatory M2 phenotype. 
When activated, microglia utilize phagocytosis as a means of attack. Additionally, the phagocytic capability of microglia, in conjunction with astrocytes, is used for clearing neuronal synapses and debris..$^{40,50}$ Failure to appropriately dispose of the neural debris as a result of microglial dysfunction or knockout has been shown to be associated with downstream synapse dysfunction, thereby drifting from homeostasis. ${ }^{40,51}$

Activated macrophages initiate the inflammatory pathway. Upon phagocytizing an invader, macrophages release pro-inflammatory cytokines, chemical messengers that alert local and systemic tissues that an immune response is underway. ${ }^{42,43,48}$ TNF- $\alpha$ and IL-6 are examples of pro-inflammatory cytokines that serve as catalysts for downstream inflammatory consequences, initiating signals that lead to swelling, fever, and additional immune cell recruitment. ${ }^{41,43}$ This leads to the translocation of additional innateassociated immune cells, including neutrophils and natural killer (NK) cells. Neutrophils primarily attack using phagocytosis, releasing enzymes that are deadly to both pathogens and the neutrophils themselves, while NK cells form a synapse with their targets and exocytose specialized secretory lysosomes, eliminating the pathogen with their cytotoxic contents. ${ }^{41,43,47}$

\subsubsection{The Adaptive Immune System}

Macrophages serve as a major player in immune system crosstalk; engaging in a role shared with dendritic cells, macrophages act as antigen-presenting cells. These innate immune cells engulf pathogens, and present the remaining antigen using their surface-bound Major Histocompatibility Complex (MHC), which interacts with extracellular T-cell Receptors (TCR) (Figure 2-1). ${ }^{42,52}$ This is the marked beginning of the activation of the antigen-specific adaptive immune system. 
The adaptive immune system is comprised of two chief cell types: T-cells and Bcells. T-cells are further differentiated into $\mathrm{CD} 4^{+}$or Helper T-cells and $\mathrm{CD} 8^{+}$or Cytotoxic T-cells. The distinct T-cell subsets allow the system to engage in a specialized attack. Specifically, CD4+ T-cells are "the quarterback of the immune system". Once activated, $\mathrm{CD}^{+} \mathrm{T}$-cells differentiate into effector and memory cells. Effector $\mathrm{CD} 4^{+} \mathrm{T}$-cells release cytokines to increase both the activation and the rate of division of B-cells and CD8 ${ }^{+} \mathrm{T}-$ cells, allowing the system to mount a stronger immune response against the pathogen. ${ }^{56}$ Conversely, activated $\mathrm{CD} 8^{+} \mathrm{T}$-cells have a more aggressive nature. The $\mathrm{CD} 8^{+} \mathrm{T}$-cells directly attack pathogens, including virally-infected or mutated cells. ${ }^{56}$ Utilizing cytotoxic enzymes, including perforin and granzyme, CD8 ${ }^{+} \mathrm{T}$-cells neutralize pathogens that express a specific antigen. ${ }^{57}$ Compared to the phagocytic cells of the innate immune system, T-cells have a greater deal of specificity, when it comes to targeting pathogens. $42,47,56$

$\mathrm{CD}^{+}$and $\mathrm{CD} 8^{+} \mathrm{T}$-cells contribute neural support, as well, providing an extra degree of surveillance within the Blood Brain Barrier. While they are neuroprotective in nature, it is of note that the cells are not necessarily always in a state primed to fight; a decrease in resting catalytic potential has been observed in CD8 ${ }^{+}$cells, likely to serve as a protective measure. ${ }^{53}$ The role of T-cells in neuroimmunity is multifaceted, and grossly ignored until recent years. T-cells have demonstrated an anti-inflammatory role, by way of IL-10 secretion, leading to a decrease in microglial-associated inflammation. ${ }^{54} \mathrm{~T}$-cell subsets have also been used in knockout studies, assessing contributions to the balance between autoimmune protection and disease..$^{55}$ 
T-cells are highly coordinated with B-cells, forming the adaptive immune system. The surface of B-cells contains antibodies, that express a heavy and light chain, with a highly-specific variable region. ${ }^{58} \mathrm{~B}$-cells can either come into direct contact with pathogens or be presented an antigen by a phagocytic cell from the innate immune system. ${ }^{52,58}$ Once stimulated, B-cells further differentiate into their effector forms, known as plasma cells. Plasma cells produce an abundance of antibodies that aid phagocytic and CD8 ${ }^{+}$T-cells in eliminating the threat. ${ }^{56}$ Both T-cells and B-cells differentiate into an effector form and a memory subset. The effector lineage is responsible for the ongoing attack against the pathogen; the memory cells are clones created to continually survey the system, allowing the immune response against subsequent encounters with the pathogen to occur more quickly. ${ }^{42,52,56,58}$

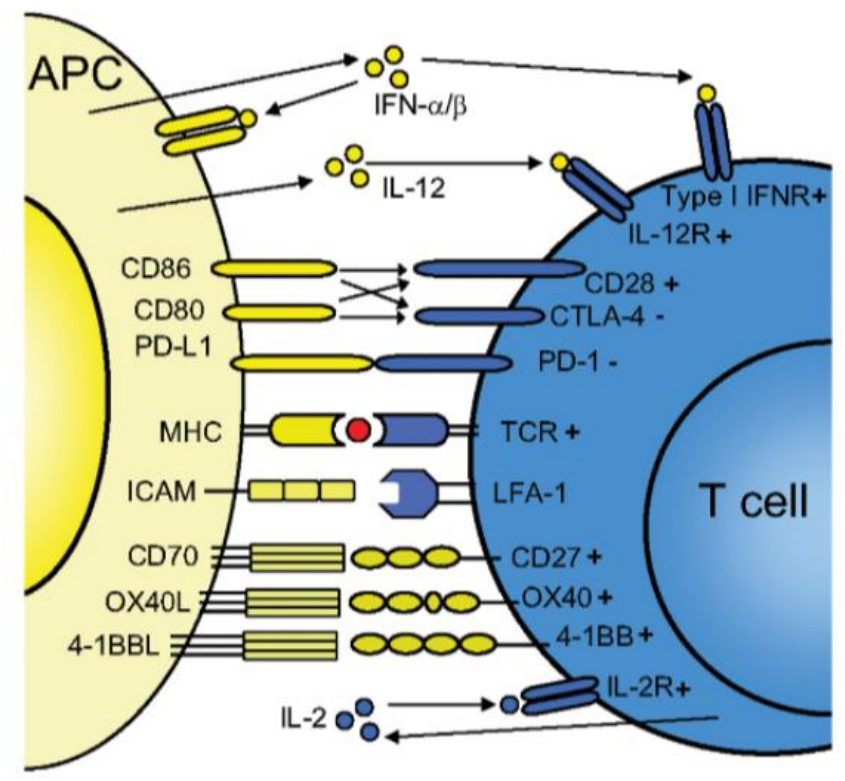

Figure 2-1 presentation of antigen from Major Histocompatibility Complex region of antigen presenting cell to the unique T-cell receptor for T-cell priming. ${ }^{52}$ 


\subsection{Psychological Stress}

\subsubsection{Definition and Prevalence of Chronic Stress}

Stress is an umbrella term, often used to describe a physiological reaction to a stressor, which is defined as an event that is perceived to drive the system away from homeostasis. ${ }^{61}$ Stressors may be routine or unpredictable, and elicit a stress mediator response, led by a molecular messenger such as a corticosteroid. This leads to an adaptive change, within the system. ${ }^{60}$ Individual instances of stress are common and can be easily adapted to, but chronic stressors can lead to overstimulation and cause a systemic deviation from baseline. ${ }^{61}$

Chronicity is a key factor when it comes to the implementation of stress models. It has been shown that a chronic stress model has the potential to cause depressive symptoms in rodents. ${ }^{62}$ One of the most widely accepted models is the unpredictable chronic mild stress (UCMS) protocol, which has been shown to sufficiently provide appropriate, exogenous stress to cause a depressive phenotype. ${ }^{63}$ In addition to its chronic approach, the UCMS protocol's unpredictable composition avoids habituation, which would ultimately blunt the stress response; this is also modified with the intensity of the stressors. ${ }^{64}$

The validity of the implementation of a stress protocol is attained with behavior testing, which uses an array of tasks to assess the acquisition of stress and depressionrelated symptoms. One of the most prevalent symptoms is the induction of anhedonia, a key component of depression that is associated with a loss in pleasurable sensation. ${ }^{68}$ The determination of coat scores, a measure of an animal's cleanliness, or lack thereof, 
is a commonly-used test to aid in determining stress - animals who show increases in stress are likely to have worse coat scores, indicating a lack of personal cleaning. ${ }^{63,69}$ Behavior testing methods are often done in a comprehensive fashion, utilizing multiple procedures to sufficiently determine the success of the protocol.

The negative impacts of chronic stress have the potential to translate systemically. In both a rodent and a human model, cardiovascular health has been shown to be an altered variable in the depression cascades. UCMS implementation has been shown to lead to vascular dysfunction in rodents and depression has been identified as a risk factor for cardiovascular disease in humans. ${ }^{66,67}$ Preliminary signs, such as increases in aggression and sleep disturbances, or decreases in sex drive, cognitive memory, sucrose preference, and food intake are measurable indicators of depression. ${ }^{70,71}$ Treatment of the depression can, notably, reverse many of these negative alterations. ${ }^{62,63,65}$ It is especially important to continue with translational studies, as an estimated $10-20 \%$ of American adults will experience major depressive disorder, indicating a surge of chronic stress. ${ }^{23,24}$

\subsubsection{Consequences of Stress on the Hypothalamic-Pituitary-Adrenal Axis}

The Hypothalamic-Pituitary-Adrenal (HPA) Axis is a neuroendocrine network that is stimulated from perceived stress, in conjunction with sympathetic nervous system activity. ${ }^{72,74,75}$ This results in the activation of the hypothalamus, a neuroendocrine tissue that releases corticotropin-releasing hormone $(\mathrm{CRH})$. $\mathrm{CRH}$ elicits downstream activation of the pituitary gland, causing the release of adrenocorticotropin hormone (ACTH). This ultimately results in the production of glucocorticoids, which are secreted by the adrenal glands. ${ }^{76}$, This response functions to increase blood glucose levels to provide the system 
with energy, while simultaneously inhibiting the release of pro-inflammatory cytokines such as TNF- $\alpha$, IL-6, and IFN- $\gamma$ and upregulating the release of anti-inflammatory cytokines IL-4 and IL-10.72 The hypothalamus detects increasing levels of cortisol, and in a negative feedback fashion, terminates the cascade - additionally, dehydroepiandrosterone (DHEA) is secreted to act as an antagonist to the glucocorticoids. ${ }^{59}$ This negative feedback loop allows the system to appropriately adjust to a perceived stress, and return to homeostasis. ${ }^{59,75,77}$

While acute stress is a part of the everyday response, chronic exposure to stress can have adverse neural, systemic, and immune consequences. ${ }^{74}$ When the negative feedback loop fails to appropriately reduce levels of glucocorticoids, hypercortisolism occurs. This chronic increase in cortisol has been shown to stunt the release of Growth Hormone and its subsequent actions, as well as DHEA and testosterone. ${ }^{76}$ Due to cortisol's immunosuppressive effects, both the actions and proliferation of the components of the innate and adaptive immune systems can be blunted, potentially leading to an immunocompromised state. ${ }^{59}$ Chronic stress can also invoke another serious phenomenon known as hypocortisolism. ${ }^{73}$ The term encompasses absolute (i.e. overall low levels) relative (i.e. lower than normal in a given situation) cortisol levels, as well as overall ability to bind; though, exact repercussions have not been thoroughly defined. ${ }^{73,77}$ In opposition to the immune response in hypercortisolism, a cortisol deficiency will lead to an influx of pro-inflammatory cytokines, subsequent recruitment of immune cells, leading to the possibility of tissue damage, metabolic dysregulation, autoimmune disease acquisition, and vascular damage..$^{59,73,78,79}$ 


\subsection{The Obese Phenotype}

\subsubsection{Collective Trends}

Clinical obesity is a state of excess adiposity that acts as a risk factor for a number of negative physiological consequences - this includes, but is not limited to, cardiovascular disease, metabolic disorders, and musculoskeletal impairments. This fat accumulation has the potential to lead to systemic dysfunction, and is especially of concern when it is accumulated in areas closer to visceral organs. ${ }^{102}$ While potentially a result of genetic or endocrine issues, obesity is often acquired as a result of malnutrition by means of excessive energy consumption and a lack of structured, planned physical activity. ${ }^{103}$ Studies have identified that nearly two thirds of the U.S. adult population is classified as overweight, with approximately $50 \%$ of them being considered obese. ${ }^{1,2,81}$ The onset of an obese phenotype has been shown to cause an increase in both endocrine activity and systemic inflammation..$^{90}$

\subsubsection{Adipokines}

The endocrine-active adipose tissue regularly secrets tissue-specific cytokines, dubbed adipokines, with the two most well-researched being leptin and adiponectin..$^{93,94,95,96}$ Having significant influences on appetite regulation and substrate metabolism, respectively, these adipokines play a huge role in establishing homeostasis in a physiological system. ${ }^{97,98}$ Interestingly, environmental alterations can have adverse effects on the functionality of these adipokines. ${ }^{99}$

Under normal circumstances, adiponectin has the potential to aid in energy conservation and attenuate insulin resistance..$^{93,95,98,100,101}$ Adiponectin can bind receptors 
AdipoR1 and AdipoR2, creating a phosphorylation cascade that mediates insulin sensitization. ${ }^{93,94}$ The molecule's dual role of being anti-inflammatory and insulinsensitizing makes it a critical adipokine..$^{93,94,95}$ However, a systemic deviation, such as excess adiposity, leads to a decrease in the concentration of circulating adiponectin, altering metabolism as a result of increased insulin resistance. ${ }^{96}$ This result is further exacerbated by an increase in another cytokine named resistin, an adipocyte-derived molecule whose concentration has an inverse correlation with insulin resistance. ${ }^{104}$ In contrast to the anti-inflammatory adiponectin, leptin has been shown to exhibit proinflammatory properties..$^{93,94,95}$ Leptin normally signals to the hypothalamus that the body has sufficient energy stored; the development of obesity leads to hypothalamic leptin resistance, and an inevitable increase in the adipokine..$^{96,97}$ This influx of leptin reinforces hypothalamic resistance, while also contributing to a pro-inflammatory environment. ${ }^{93,94,95}$

\subsubsection{Consequences of Obesity}

The establishment of systemic homeostasis is highly dependent on the physiological environment. Under normal conditions, many systems work in synergy to attain a homeostatic phenotype. This balance is a result of a specific coordination between both central and peripheral branches. Chapelot and Charlot specified six vital systems that contribute to homeostasis (Figure 2-2). ${ }^{80}$

Adipose tissue is a vital structure that has been well-documented for serving thermogenic and metabolic purposes; while it is commonly known as a means of storing energy, adipose tissue is also recognized as an endocrine organ. By releasing hormones and adipokines, including leptin and adiponectin, adipose tissue has a significant influence on metabolic homeostasis. ${ }^{82,83}$ However, while it is necessary for survival, 
excessive amounts of the lipid-rich tissue can lead to negative consequences. The accumulation of adipose tissue, by way of adipocyte hypertrophy and adipocyte hyperplasia, leads to the onset of obesity. ${ }^{82,84}$

Excessive adiposity has the potential to induce insulin resistance. Insulin is a key metabolic mediator that is released from pancreatic $\beta$-cells, in response to a rise in blood glucose. ${ }^{81,85,86}$ Insulin's cell receptor is an $\alpha_{2} \beta_{2}$ disulfide-linked heterodimer, a transmembrane protein with an extracellular insulin binding site. ${ }^{86}$ Insulin causes a conformational change to its respective receptor, leading to autophosphorylation and subsequent phosphorylation of IRS1/2 and further downstream molecules. ${ }^{85,86}$ This cascade leads to the translocation of the GLUT-channels, which allow glucose to move from the blood, into the cell; this cascade is disrupted in the obese phenotype..$^{81,87}$ The ongoing systemic inflammation can weaken insulin's ability to bind to a receptor, and can lead to dephosphorylation of intermediates. The shift in the environment is largely attributed to an imbalance of pro and anti-inflammatory cytokines, resulting from the accumulation of fat, causing a state of systemic inflammation. ${ }^{87}$ The obese phenotype has been shown to lead to an increase in myeloid-derived M1 macrophages; unlike their M2 counterparts, M1 macrophages exacerbate inflammation, releasing cytokines that continue to propagate a systemic immune response. $83,88,89,90,91$ This translates to a subsequent increase in the adaptive immune response, especially CD8 ${ }^{+} \mathrm{T}$-cells. As a result, anti-inflammatory molecules, such as adiponectin and IL-10, are overpowered. ${ }^{92}$ 


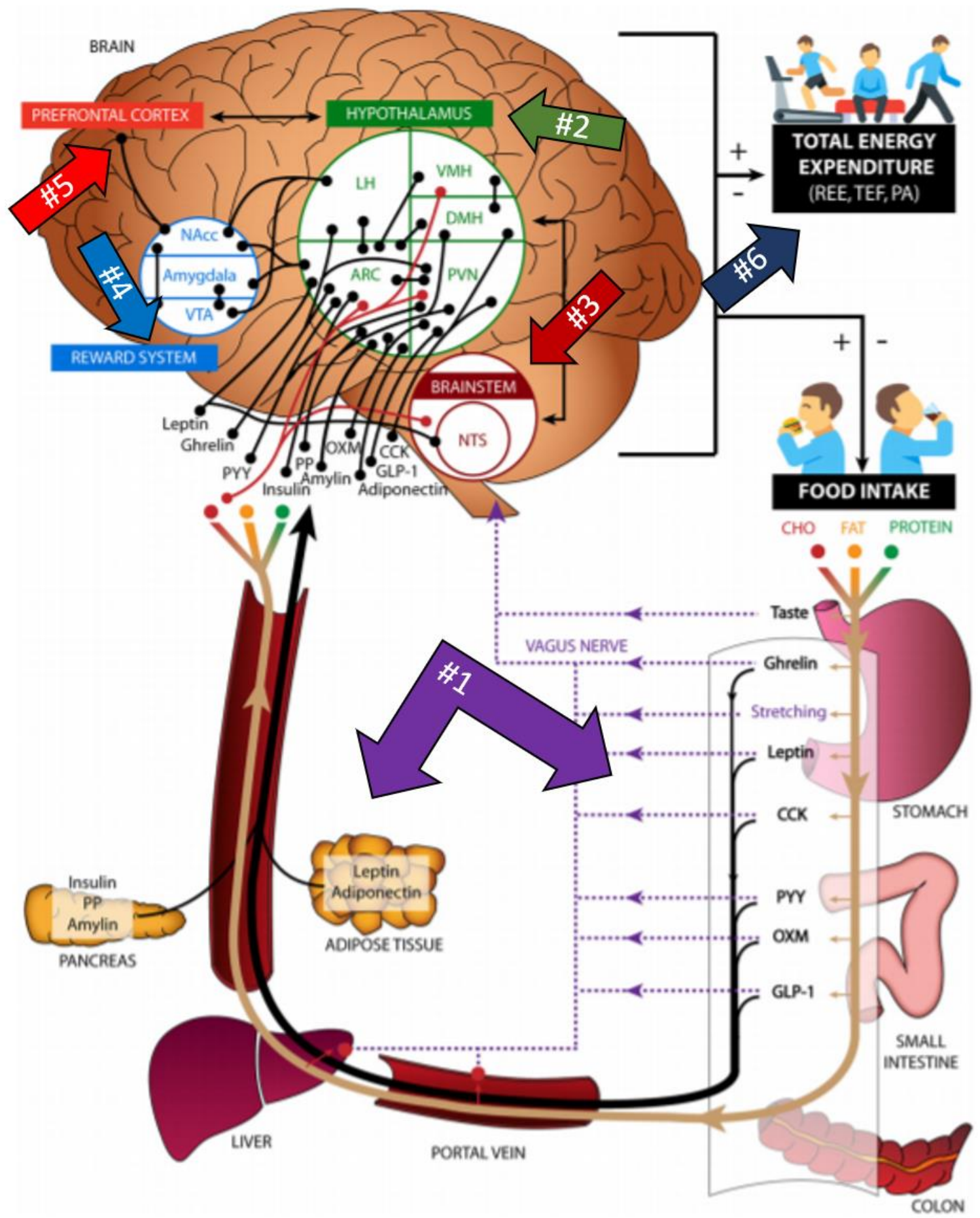

Figure 2-2 showcases the complex interplay of a multitude of systems providing feedback to attain systemic homeostasis. The six specified contributors are: 1) afferent network of hormones and neurons, 2) the hypothalamus, 3) the brain stem, 4) the reward system, 5) the prefrontal cortex, 6 ) the sympathetic nervous system. ${ }^{80}$ 


\subsection{Oxidative Stress}

\subsubsection{Physiological Mechanisms}

Oxidative stress is the physiological imbalance between ROS/free radicals and antioxidants, within a system. ROS are derivatives of oxygen that contain unpaired electrons: common examples include superoxide anion $\left(\mathrm{O}_{2 .}{ }^{-}\right)$, hydrogen peroxide $\left(\mathrm{H}_{2} \mathrm{O}_{2}\right)$, hydroxyl radical (OH.), and nitric oxide (NO.). ${ }^{-123}$ ROS are a common byproduct of aerobic metabolism; during oxidative phosphorylation, the creation of the proton gradient assists in the production of ATP. ${ }^{121,122,123}$ However, the system will have occasional errors, resulting in an incomplete transfer of available electrons within the electron transport chain. In addition, they can be a byproduct of enzymatic pathways, including the NADPH oxidase and XO pathways. ${ }^{122,123}$ While an excess of ROS can be damaging, these compounds assist in maintaining homeostasis; one such example being the generation of nitric oxide to stimulate vasodilation.

In a homeostatic environment, excess ROS are nullified by antioxidants, including vitamins $A, C, E$, and also glutathione. ${ }^{121,122,123}$ Additionally, select enzymes scavenge for free radicals, to prevent excessive accumulation. Indeed, proteins including catalase, superoxide dismutase, and glutathione peroxidase work to prevent an overabundance of free radicals. ${ }^{121-124}$ When an unbalanced system allows them to accumulate, free radicals can cause severe cellular and tissue damage. With a goal of capturing an electron, free radicals can commence lipid peroxidation; the double bond of an unsaturated fatty acid of the plasma membrane is often the target, leading to the potential of damaging the cell membrane. ${ }^{121-124}$ In addition, ROS can in engage with proteins. These radicals form covalent bonds with proteins, aiming to steal an electron. This binding process has the potential to disturb both the active site or the overall conformation of the protein, and may 
render it useless. ${ }^{122,123}$ In a similar manner, ROS can lead to DNA damage; this can lead to mutation of the DNA, or overall breaking of the strands. ${ }^{121-124}$

\subsubsection{Xanthine Oxidase and Febuxostat Attenuation}

$\mathrm{XO}$ is a major enzymatic source of ROS. The starting material of the pathway is hypoxanthine, a derivative of adenosine. XO catalyzes the reaction in a two-step process, resulting in uric acid and the creation of free radicals. ${ }^{122,123}$ Indeed, cardiovascular dysfunction has been linked to the uric acid pathway, with $\mathrm{XO}$ being the primary problem. ${ }^{127}$ From a pharmacological standpoint, delivery of anti-inflammatory and antihypertension drugs can increase vascular reactivity and reduce vascular stiffening, respectively. ${ }^{128}$ XO's activity can be reversibly inhibited by the drug febuxostat, decreasing the end production of ROS. ${ }^{35,126}$ Febuxostat acts by blocking the conversion of hypoxanthine to xanthine and xanthine to uric acid. As a therapeutic agent, febuxostat delivery has been shown to attenuate atherosclerosis in mice, decreasing ROS production and returning vascular dilatory capacity. ${ }^{34}$ Febuxostat has been shown to be particularly effective in attenuating XO activity in pathological states, and decreases ROS production in vascular endothelium. ${ }^{129}$
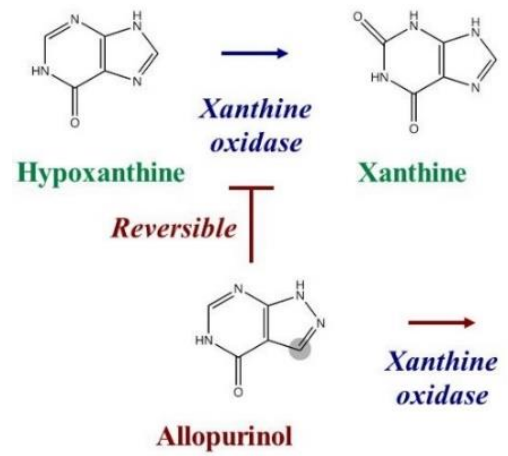

Xanthine



Febuxostat

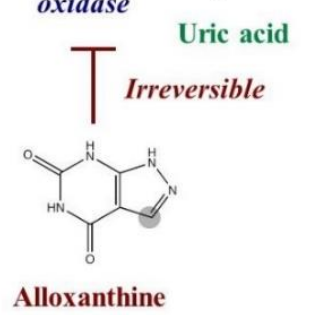

Figure 2-3 Febuxostat causes reversible inhibition of xanthine oxidase action. 


\section{Chapter 3}

\section{Methods}




\subsection{Animal Models}

Mice $(n=24)$, aged 16 weeks, arrived at the West Virginia University Health Sciences Center from the Jackson Laboratory, and were fed a standard diet to retain a lean phenotype. An additional 24 mice, aged 6 weeks, arrived from the Jackson Laboratory, and were placed on a high-fat diet (60 kcal\% fat) to induce obesity (Research Diets, New Brunswick, NJ, D12492). Half of the animals in each cohort were chronically delivered febuxostat in their water bottles. The lean animals were then separated into one of four groups: 1) lean control, 2) lean control + febuxostat, 3) lean UCMS, 4) lean UCMS + febuxostat. The obese counterparts were also separated into four groups: 1) obese control, 2) obese control + febuxostat, 3) obese UCMS, 4) obese UCMS + febuxostat. All mice received chow and water ad libitum, and protocols received approval from the West Virginia University Health Sciences Center Animal Care and Use Committee prior to experimentation.

\subsection{UCMS Protocol}

The UCMS Protocol was developed to produce depression-like behaviors in rodents. This approach is the most appropriate model for clinical depression in rodents and mimics human-like depression behaviors, including anhedonia and learned helplessness. During the UCMS protocol, mice were singly-housed, and randomly exposed to the following mild environmental stressors for 7 hours each day, 5 days per week, over the 8-week course:

1. Damp bedding - $10 \mathrm{oz}$. of water was added to each standard cage 
2. Bath - all bedding was removed and $\sim 0.5$ inches of water was added to the empty cage. Water temperature was at room temperature, $\sim 24^{\circ} \mathrm{C}$

3. Cage tilt - cage was tilted to $45^{\circ}$ without bedding

4. Social stress - each rat was switched into a cage of a neighboring rat

5. No bedding - all bedding was removed from the cage

6. Alteration of light/dark cycles - turning the lights off/on in random increments for a scheduled period

\subsection{Coat Scores}

To validate the unpredictable chronic mild stress paradigm, animal coat scores were assessed at 8 anatomical sites (head, neck, back, stomach, tail, forelimbs, hindlimbs, and genitals). Scoring was binary with 0 meaning "clean", and 1 equating to "dirty". The sum of the 8 sites equaled the coat score.

\subsection{Flow Cytometry}

\subsubsection{Spleen Processing}

Following terminal procedures, the spleen was removed and placed in a weigh boat containing $3 \mathrm{~mL}$ of Roswell Park Memorial Institute medium (RPMI) and placed on ice. Using two glass microscope slides, the spleen was thoroughly crushed, and filtered through a $70 \mu \mathrm{m}$ strainer, into a $50 \mathrm{~mL}$ conical. The sample was then spun down at 1500 RPM for 5 minutes, and the resultant supernatant was poured off. The remaining pellet was re-suspended in $3 \mathrm{~mL}$ of tris-buffered ammonium chloride, vortexed, and placed on ice for 10 minutes, while red blood cell lysis occurred. The total volume of the solution 
was then doubled by adding RPMI, and re-centrifuged at 1500 RPM for 5 minutes. The supernatant was then discarded, and the remaining leukocytes were re-suspended in 5 $\mathrm{mL}$ of RPMI. Samples were left on ice until the other tissues were prepared.

\subsubsection{Brain Homogenization}

After terminal procedures, the brain was removed and transferred to a weigh boat containing $2 \mathrm{~mL}$ of ice cold RPMI, and placed on ice. Using a clean razor blade, the brains were minced into a fine consistency, and transferred to a gentleMACS C tube. Next, $300 \mu \mathrm{L}$ of DNase and $150 \mu \mathrm{L}$ of collagense were added into each tube, and the total volume was brought up to $5 \mathrm{~mL}$ with additional RPMI. Tubes were then transferred to and started on the gentleMACS Program 37C_ABDK_01 for 30 minutes.

\subsubsection{Brain Immune Cell Isolation}

Following the incubation, the resultant solution was filtered using a $70 \mu \mathrm{m}$ strainer, into a clean $50 \mathrm{~mL}$ conical. Using RPMI, the total volume was brought up to $10 \mathrm{~mL}$. The samples were then centrifuged at 1500 RPM for 5 minutes at $4^{\circ} \mathrm{C}$. Following the centrifugation, the supernatant liquid was removed from the remaining pellet. The pellet was then re-suspended in $4 \mathrm{~mL}$ of $70 \%$ isotonic percoll. In a clean $15 \mathrm{~mL}$ conical, $7 \mathrm{~mL}$ of $30 \%$ percoll was added, with the newly-suspended pellet being added as an underlay. The conical was centrifuged at $500 \times \mathrm{xg}$ for 20 minutes at $22^{\circ} \mathrm{C}$ with an acceleration of 4 and break of 0 . This centrifugation resulted in the establishment of a gradient, with immune cells residing in a foam-like appearance in the middle. The cells were extracted 
using a pipette with a beveled tip, transferred to a $15 \mathrm{~mL}$ conical, and placed on ice. The tubes were brought up to $9 \mathrm{~mL}$ with RPMI and spun down at $400 \mathrm{xg}$ for 5 minutes at $4^{\circ} \mathrm{C}$. The resultant supernatants were discarded, and the remaining pellets were suspended in $1 \mathrm{~mL}$ of RPMI.

\subsubsection{Cell Counting}

Cells were diluted to count on the hemocytometer, with a 1:2 dilution used for the brain $(10 \mu \mathrm{L}$ of sample $+10 \mu \mathrm{L}$ of dye) and a 1:100 dilution used for the spleen $(1 \mu \mathrm{L}$ of sample $+99 \mu \mathrm{L}$ of dye). Samples were loaded on the hemocytometer and counted under the microscope. The 16-block quadrants were counted and used to estimate the number of cells $/ \mathrm{mL}$ of sample:

$$
\begin{aligned}
& \frac{\text { Sum of \# of cells counted }}{\# \text { of quadrants counted }} * \text { dilution factor } * 10^{4}=\# \text { of cells } / 1 \mathrm{~mL} \\
& \frac{\# \text { of desired cells }}{x}=\frac{\# \text { of cells }}{1 \mathrm{~mL}} \quad \rightarrow \quad x=\frac{\# \text { of desired cells }}{\# \text { of cells }}
\end{aligned}
$$




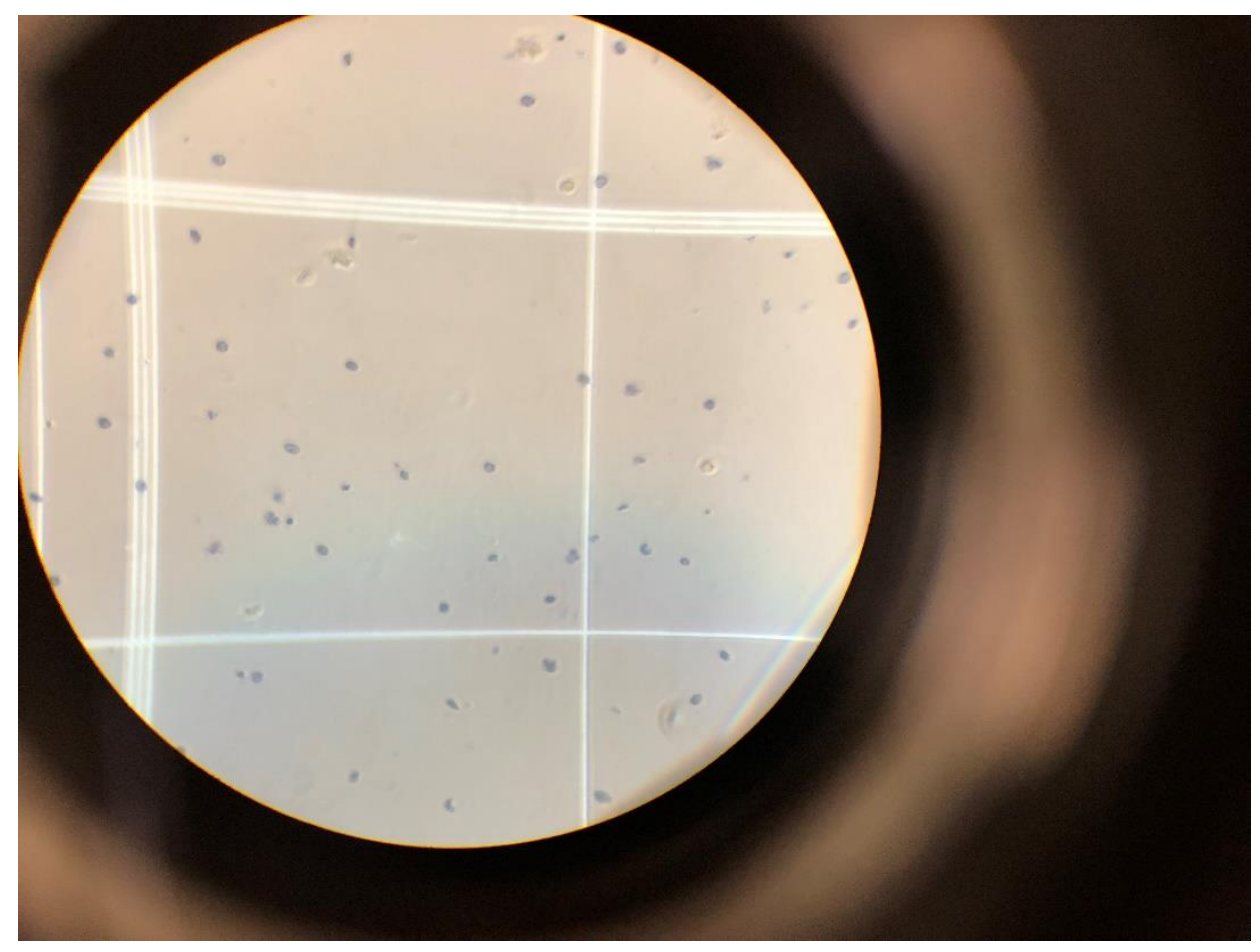

Figure 3-1 Stained spleen cells magnified under microscope

\subsubsection{Cell Staining}

After volumes were calculated, with respect to the desired number of cells, single stain controls and experimental samples were added to a 96-well plate. Calculated volumes were added to each well, and each sample was washed by adding $100 \mu \mathrm{L}$ of phosphate-buffered saline with azide (PBS-Az), followed by centrifugation at 1500 RPM, at $4^{\circ} \mathrm{C}$, for 5 minutes. The resulting supernatant was disposed of and the wash was repeated with $200 \mu \mathrm{L}$ of PBS-Az. The cells were then blocked with mouse Fc Block (CD16/CD32, BD Biosciences) and incubated on ice for 15 minutes. Cells then underwent surface staining with fluorescently-tagged antibodies: CD45-BB700 (BioLegend), CD11bPE-Cy5 (BioLegend), Ly-6C-PE-CF594 (BD Biosciences), Ly-6G-APC-Vio770 (Miltenyi 
Biotec), CD11c-BV480 (BD Biosciences), CD206-PE-Cy7 (BioLegend), CD4-FITC (Miltenyi Biotec), CD3e-PE (Miltenyi Biotec), CD8a-APC (Miltenyi Biotec), and CD45RAlexa Fluor 700 (Thermo Fisher Scientific). Following a 30 minute incubation, the cells were washed $3 x$ as described above, using $200 \mu \mathrm{L}$ of PBS-Az. After the final wash, $100 \mu \mathrm{L}$ of $2 \%$ paraformaldehyde was added to each well, for overnight fixing of the cells.

\section{Antibodies}

Antibody markers were utilized to identify specific immunological cell types within the tissues (Table 3-1).

Table 3-1: Antibody-to-cell type pairings

\begin{tabular}{|l|l|}
\hline \multicolumn{1}{|c|}{ Antibody } & \multicolumn{1}{|c|}{ Cell Type } \\
\hline $\mathrm{CD}^{\prime} 5^{+}$ & General White Blood Cells \\
\hline$\left(\mathrm{CD}^{+} 5^{+}\right) \mathrm{CD}^{+}$ & General T-Cells \\
\hline$\left(\mathrm{CD}^{+} 5^{+} \mathrm{CD}^{+}\right) \mathrm{CD}^{+}$ & Helper-T Cells \\
\hline$\left(\mathrm{CD}^{+} 5^{+} \mathrm{CD}^{+}\right) \mathrm{CD}^{+}$ & Cytotoxic-T Cells \\
\hline$\left(\mathrm{CD}^{+} 5^{+}\right) \mathrm{CD}^{+} 5 \mathrm{R}^{+}$ & B-Cells \\
\hline$\left(\mathrm{CD} 45^{+}\right) \mathrm{CD}^{+} 1 \mathrm{c}^{+} \mathrm{CD} 206^{-}$ & \\
\hline$\left(\mathrm{CD} 45^{+}\right) \mathrm{CD} 206^{+} \mathrm{CD} 11 \mathrm{c}^{-}$ & M1 Macrophages (pro-inflammatory) \\
\hline
\end{tabular}




\subsubsection{BD LSRFortessa}

Following a 12-hour minimum membrane fixation, samples were transferred from their respective wells to test tubes, using $300 \mu \mathrm{L}$ of PBS-Az for each well. The samples were run on the BD LSRFortessa, which utilizes a spectrum of lasers to excite the fluorescent tags. By utilizing a blank control and an array of single stain controls, the LSRFortessa was able to measure the wavelengths of the excited fluorescent markers, determining the profile of cell type percentages in the samples.

\subsection{Data analysis}

\subsubsection{Gating strategies}

After the samples were run on the LSRFortessa, data files were produced, which were used to quantify the percentages of immune cell populations. Figure 3-2 shows the gating strategy used to discriminate between cell types. The FCS Express 6 Flow Research Edition software was utilized for analysis. Beginning with the inclusion of all cells, gates were able to be created to exclude cells based on their fluorescent tag. This allowed for the discrimination of each cell type of interest. 

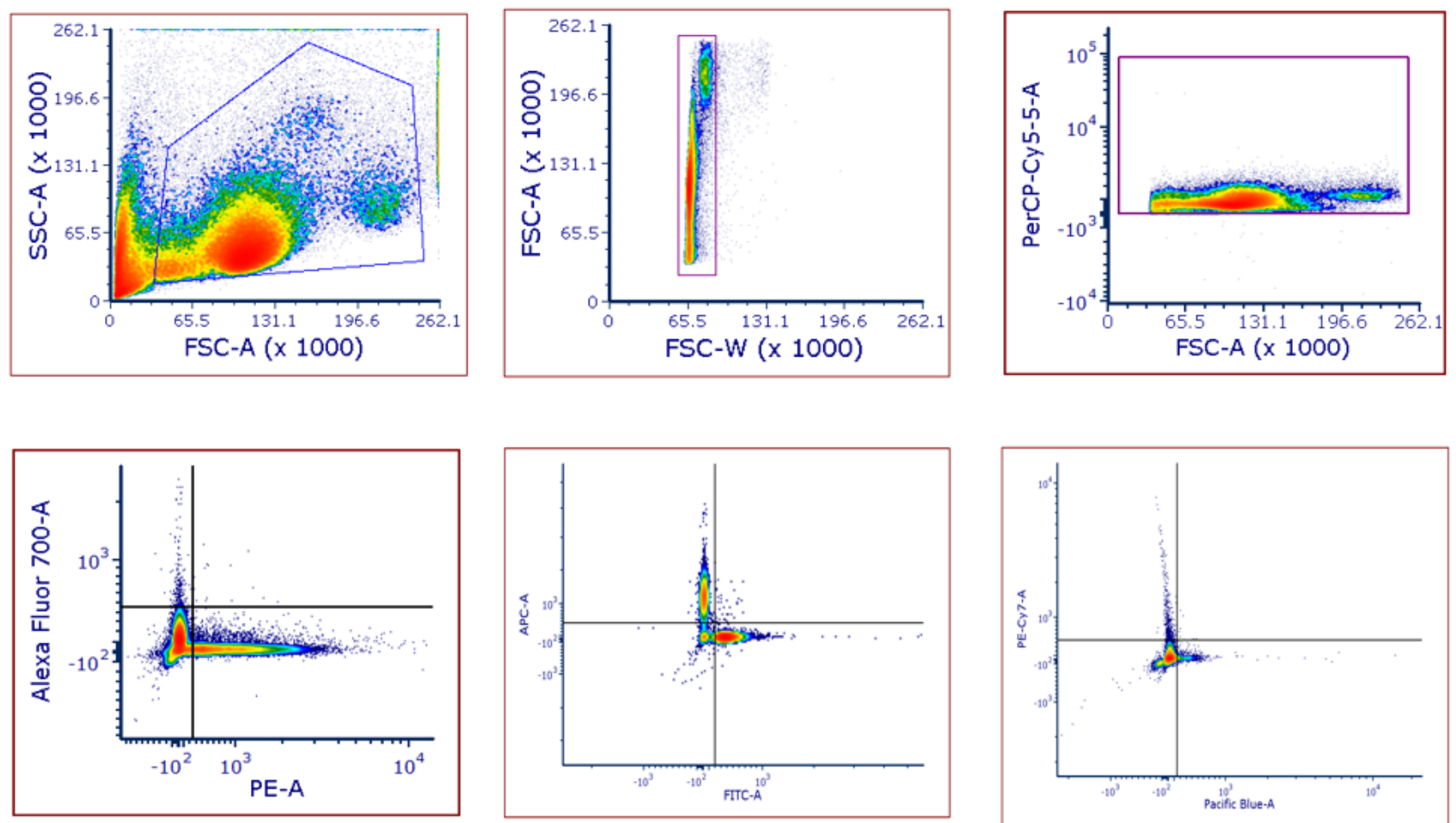

Figure 3-2 Gating strategy to determine cell populations obtained from LSRFortessa using FCS Express 6 Flow Research Edition software.

\subsubsection{Data and Statistical analysis}

All data are presented as mean \pm SEM. Normality was evaluated by the KolmogorovSmirnov test. Anthropometric assessments were analyzed by analysis of variance (ANOVA) for UCMS condition, as well as by analysis of co-variance (ANCOVA) for exposure by obesity. The distribution of immune populations were examined based on specific aims. A One-way ANOVA was used to compare the differences between lean and obese groups in the presence and absence of febuxostat, and a Tukey post-hoc test to determine differences between groups. Similarly, comparisons between control and UCMS groups (by lean or obese group) with or without febuxostat was examined by two-way ANOVA with a Tukey post-hoc. In all cases, $\mathrm{p} \leq 0.05$ was taken to reflect statistical significance. 


\section{Chapter 4}

\section{Results}




\section{Results}

\section{Animal Characteristics}

Implementation of the high-fat diet resulted in significant increases in body mass between lean and obese animals. The addition of the UCMS protocol to the obese mice resulted in a significant decrease in end mass that was not seen in any of the other groups (Table 4-1).

Table 4-1: Animal Characteristics

\begin{tabular}{|c|c|c|}
\hline & Lean Mass (g) & Obese Mass (g) \\
\hline Control $(n=6)$ & $28.4 \pm 0.8 *$ & $48.4 \pm 0.7 * *$ \\
\hline Control+Feb $(n=6)$ & $27.9 \pm 1.1 *$ & $51.4 \pm 1 * *$ \\
\hline UCMS (n=6) & $26.7 \pm 1.8 *$ & $41.5 \pm 0.8$ \\
\hline UCMS+Feb (n=6) & $28.8 \pm 08 *$ & $45.5 \pm 3.1 * *$ \\
\hline \multicolumn{3}{|c|}{${ }^{*} p<0.0001$ vs Obese Control; ${ }^{*} p<0.05$ vs Obese UCMS } \\
\hline
\end{tabular}


Coat Scores

Coat scores were collected to assess acquistion of depressive phenotype. UCMS significanlty increased coat score values in both lean and obese groups (Table 4-2).

Table 4-2: Coat Scores

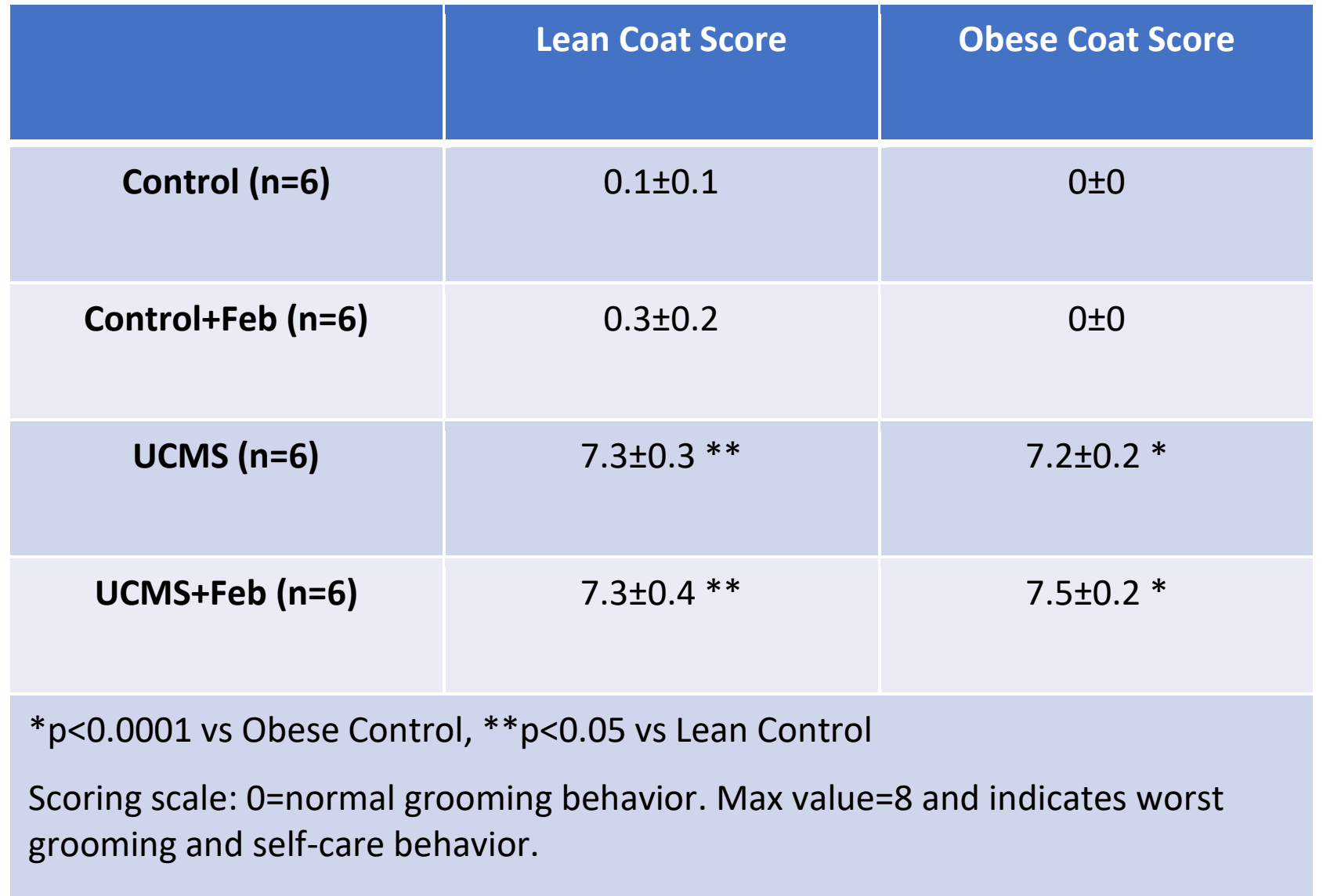


Figure 4-1 shows the changes observed in total white blood cells $\left(C D 45^{+}\right)$for lean and obese mice, with and without febuxostat treatment. Obese controls had significantly less $\mathrm{CD}_{4} 5^{+}$cells than their lean counterparts $(p<0.05)$. In contrast, the febuxostat treatment did not result in any significant differences in the prevalence of CD45 ${ }^{+}$cells, in either lean or obese mice.

After identifying the white blood cells, specific cell populations were parsed out. In Figure 4-2, T-cells and T-cell subsets were examined. Compared to lean mice, obese mice had significantly lower $C D 3^{+}$cells $(p<0.05)$, indicating an overall decrease in total Tcell populations (Fig. 4-2A). In the obese control group, there was a significant increase in positive staining for both $C D 4^{+}$cells $(p<0.01$; Fig. $4-2 B)$ and $C D 8^{+}(p<0.05$, Fig. $4-2 C)$ compared to lean controls. The ratio of $\mathrm{CD}^{+}$to $\mathrm{CD} 8^{+}$cells was also calculated, with higher numbers being associated with an anti-inflammatory phenotype and lower numbers being associated with a pro-inflammatory phenotype. Between the lean and obese groups, no statistically significant differences were observed in the $\mathrm{CD} 4^{+}$to $\mathrm{CD} 8^{+}$ ratio (Fig. 4-2D). The addition of febuxostat did not result in any statistically significant differences in $\mathrm{CD}^{+}, \mathrm{CD}_{4}^{+}$, or $\mathrm{CD} 8^{+}$cells, nor in the $\mathrm{CD} 4^{+}$to $\mathrm{CD} 8^{+}$ratio.

In addition to T-cells and their subsequent populations, B-cells $\left(C D 45 R^{+}\right)$were identified (Figure 4-3). The percentage of B-cells was shown to be significantly lower in the obese controls' brains, compared to lean controls $(p<0.05)$. Febuxostat treatment did not result in any significant differences in CD45R+ cells, in either lean or obese mice.

Figure 4-4 examines macrophage populations, specifically focusing on the proinflammatory M1 phenotype (CD11 $\left.\mathrm{C}^{+} \mathrm{CD} 206^{-}\right)$versus the anti-inflammatory M2 phenotype $\left(C D 206{ }^{+}{ }^{C D 11 c}\right)$. No statistically significant differences were observed in the $M 1$ 
populations in the lean and obese control groups (Fig. 4-4A), though the obese controls showed a significant decrease $(p<0.05)$ in $M 2$ populations (Fig. 4-4B). The M1 to M2 ratio was also calculated, with higher values corresponding to a pro-inflammatory environment, and lower values being associated with an anti-inflammatory environment. There were no significant differences amongst the lean and obese controls (Fig. 4-4C). Febuxostat treatment did not result in any significant differences in M1 or M2 macrophages, or the M1 to M2 ratio.

Effects of Chronic Febuxostat Treatment on Brain Immune Cell Populations and the Role of Obesity



Figure 4-1: Percentage of white blood cells $\left(C D 45^{+}\right)$in lean and obese animals with febuxostat (Non-UCMS+Feb) treatment. ${ }^{*} p<0.05$ vs lean control (NonUCMS). $n=4-5$ per group. 

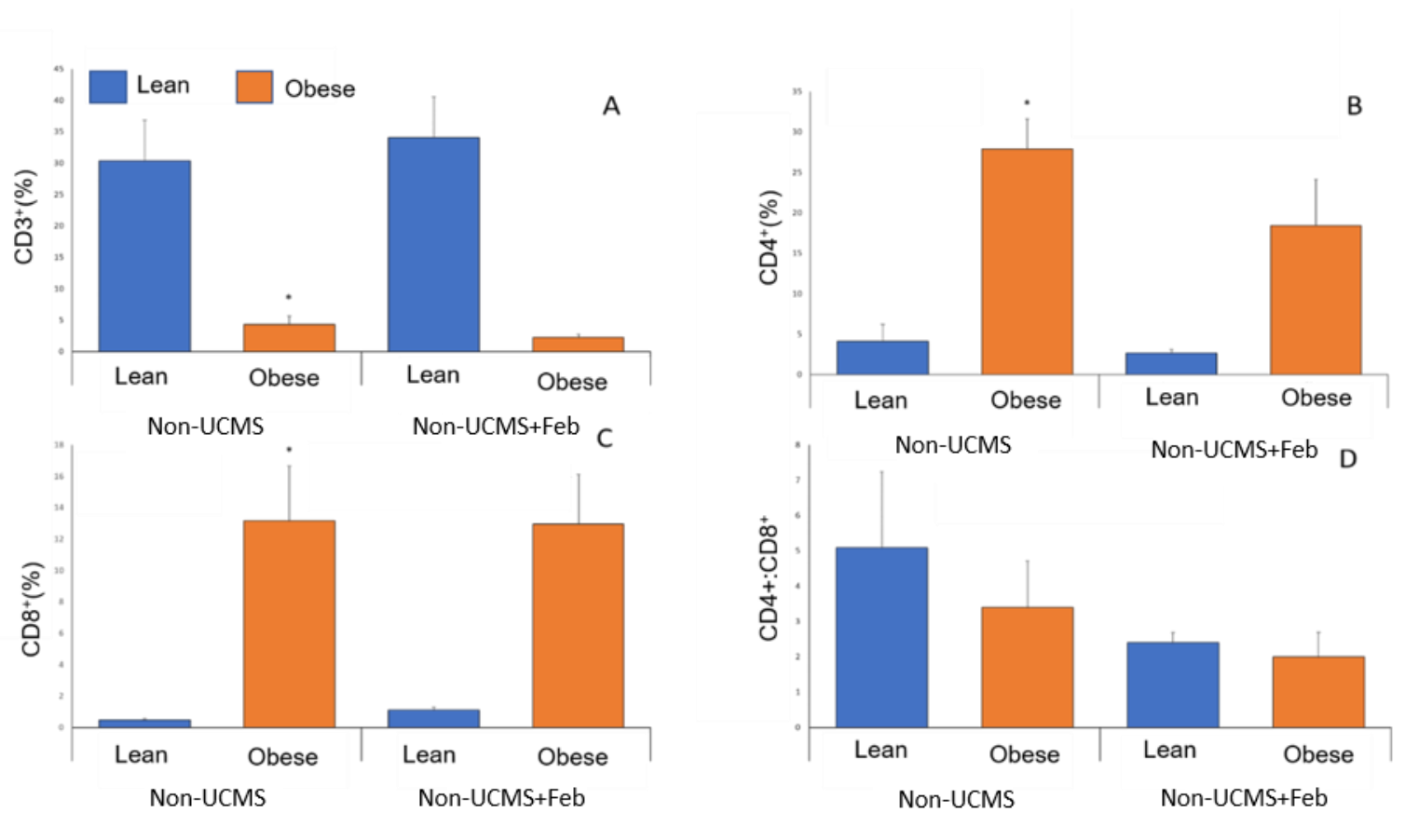

Figure 4-2: Percentage of A) T-cells $\left(\mathrm{CD}^{+}\right)$, B) Helper-T cells $\left(\mathrm{CD} 4^{+}\right)$, C) Cytotoxic- $\mathrm{T}$ cells $\left(\mathrm{CD} 8^{+}\right)$, and $\left.\mathrm{D}\right)$ the $\mathrm{CD} 4^{+}$to $\mathrm{CD} 8^{+}$ratio (an indicator of inflammation) in lean and obese animals with febuxostat (Non-UCMS+Feb) treatment. $p<0.05$ vs lean control (NonUCMS). $n=4-5$ per group.



Figure 4-3: Percentage of B-cells $\left(C D 45 R^{+}\right)$in lean and obese animals with febuxostat treatment (Non-UCMS+Feb). $p<0.05$ vs lean control (Non-UCMS). $n=4-5$ per group. 


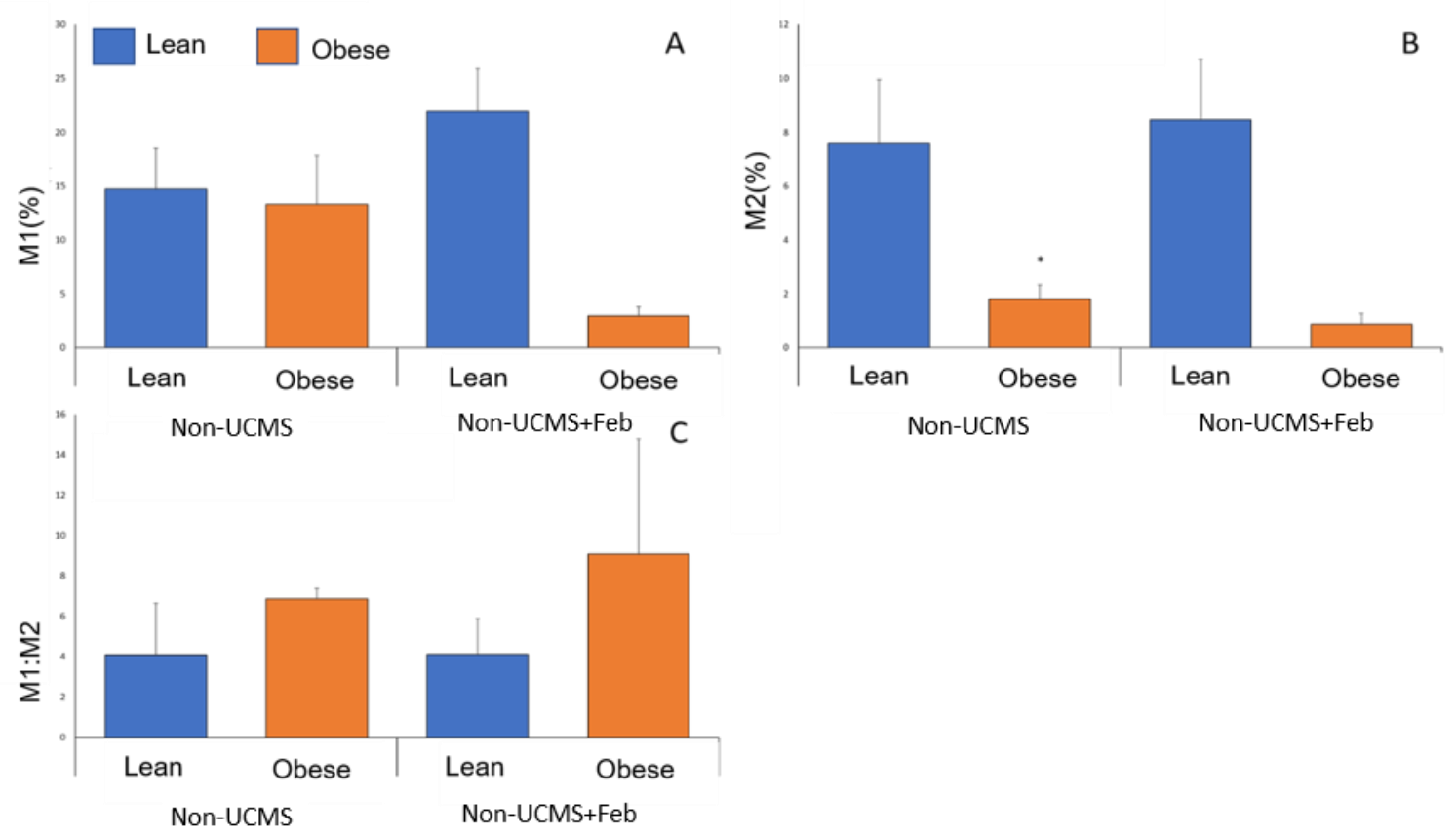

Figure 4-4: Percentage of A) M1 macrophages, B) M2 macrophages, C) the M1/M2 ratio (an indicator of inflammation) in lean and obese animals with febuxostat treatment (NonUCMS+Feb). $p<0.05$ vs lean controls (Non-UCMS). $n=4-5$ per group.

Effects of UCMS on Brain Immune Cell Populations in Lean and Obese Mice

Figure 4-5 represents the $\mathrm{CD}_{4} 5^{+}$populations in controls versus UCMS implementation. No significant differences were observed between the lean controls and the lean UCMS mice. In comparison to the obese controls, the obese UCMS cohort showed a significant increase in total white blood cells $(p<0.01)$.

T-cell populations were also identified, as seen in Figure 4-6. In terms of total Tcells $\left(\mathrm{CD}^{+}\right)$, there were no significant differences between the lean and obese controls compared to the UCMS groups (Fig. 4-6A). As such, CD4 ${ }^{+}$cells, CD8 ${ }^{+}$cells, and the CD4 ${ }^{+}$ 
to $\mathrm{CD}^{+}$ratio was similar between lean and obese controls vs. UCMS groups (Fig. 4-6B4-6D).

Figure 4-7 shows the populations of CD45R ${ }^{+}$cells (B-cells). UCMS implementation did not significantly alter the B-cell populations in the lean cohort. While not statistically significant, the obese UCMS group exhibited a downward trend, in comparison to the nonstressed obese group.

M1 and M2 macrophages are represented in Figure 4-8. Figure 4-8A shows the M1 phenotype, in which a positive trend was observed between lean controls and the lean UCMS group. However, no differences were noted between obese controls and obese UCMS group. In regard to M2 macrophages, there was no significant difference observed between the lean controls and lean UCMS groups (Fig 4-8B) and no differences were noted in the M1 to M2 ratio (Fig. 4-8C). However, the obese UCMS cohort experienced a significant decrease $(p<0.05)$ in comparison to obese controls (Fig. 4-8B). However, the UCMS protocol did not result in differences in the M1 to M2 ratio (Fig. 4$8 C)$. 


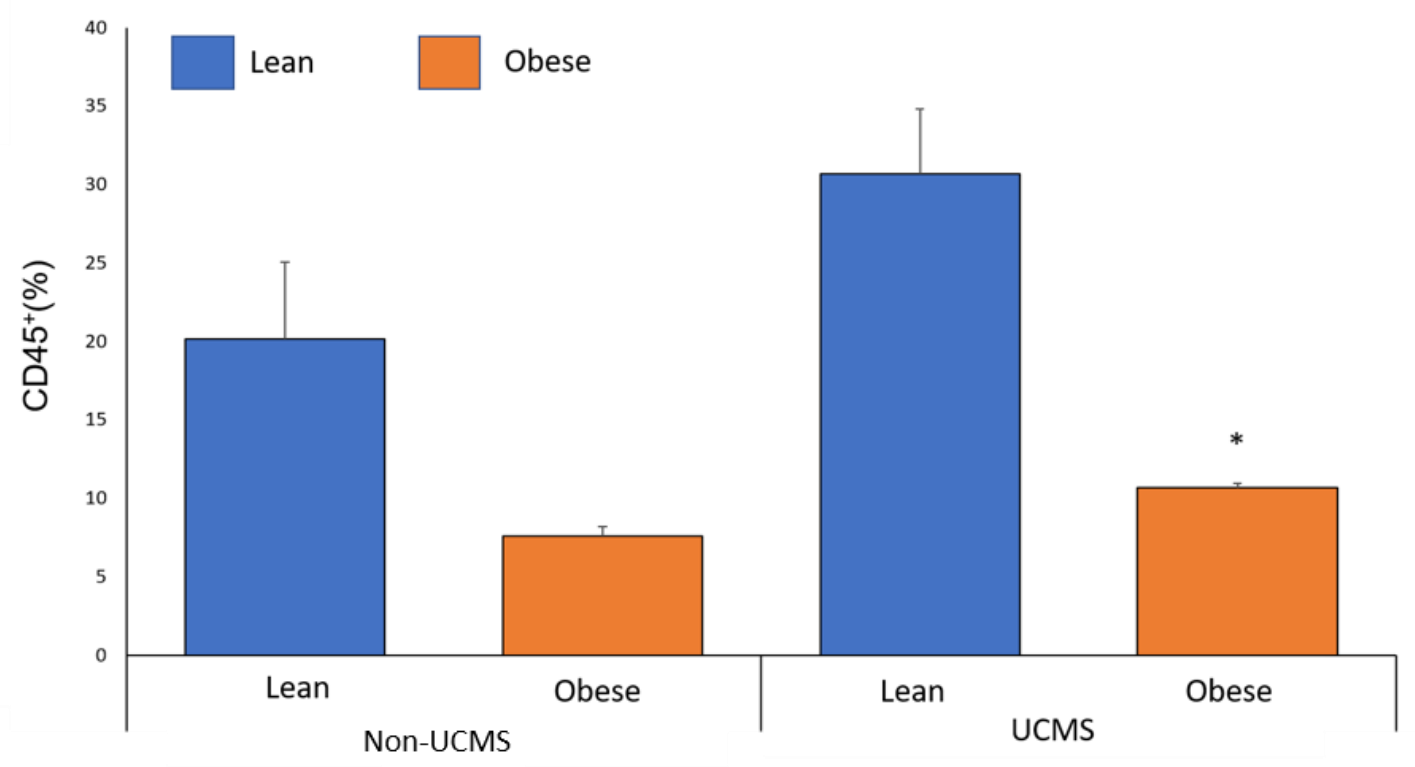

Figure 4-5: Percentage of white blood cells (CD45+) in lean and obese animals with UCMS. ${ }^{*} \mathrm{p}<0.05$ vs obese control (Non-UCMS). $n=4-5$ per group.
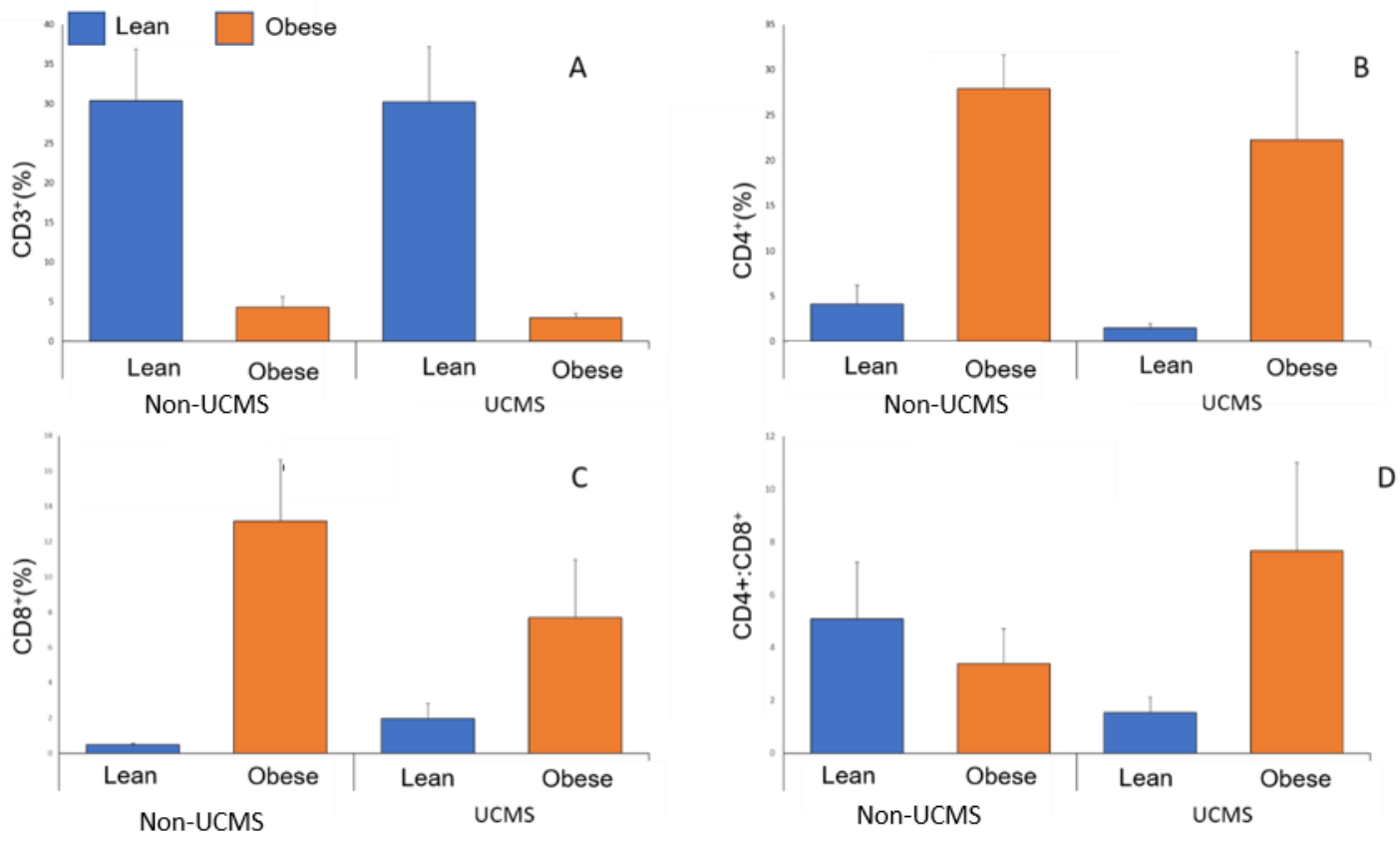

Figure 4-6: Percentage of A) T-cells $\left(\mathrm{CD}^{+}\right)$, B) Helper-T cells $\left.\left(\mathrm{CD} 4^{+}\right), \mathrm{C}\right)$ Cytotoxic-T cells $\left(\mathrm{CD} 8^{+}\right)$, and $\left.\mathrm{D}\right)$ the $\mathrm{CD} 4^{+}$to $\mathrm{CD} 8^{+}$ratio (an indicator of inflammation) in lean and obese animals with UCMS. $n=4-5$ per group 




Figure 4-7: Percentage of B-cells $\left(C D 45 R^{+}\right)$in lean and obese animals with UCMS. $n=4-$ 5 per group.

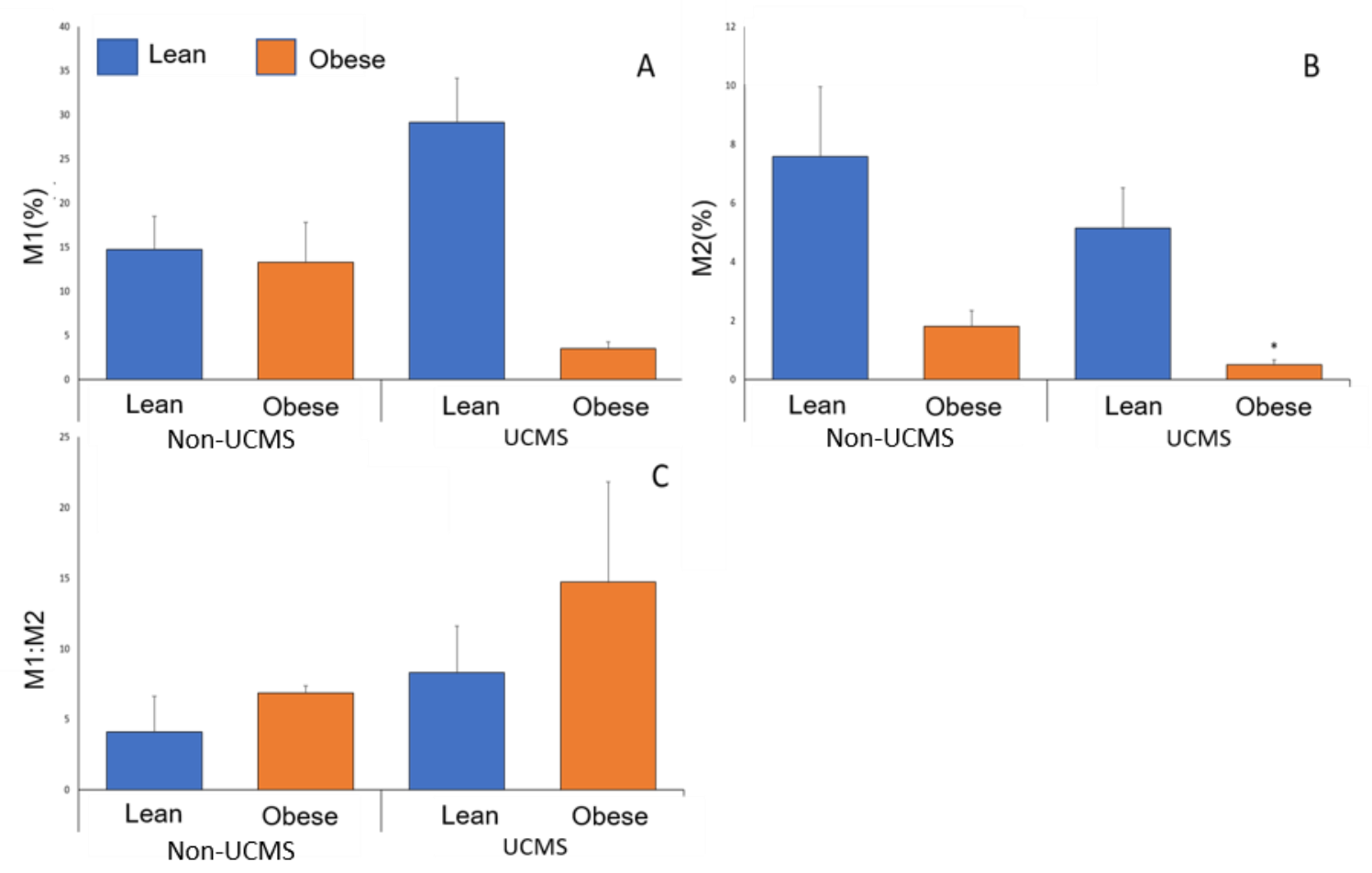

Figure 4-8: Percentage of A) M1 macrophages, B) M2 macrophages, C) the M1/M2 ratio (an indicator of inflammation) in lean and obese animals with UCMS. $p<0.05$ vs obese controls (Non-UCMS). $n=4-5$ per group. 
Effects of Febuxostat Treatment on Brain Immune Cell Populations in Lean and Obese Mice with UCMS

Expanding on the UCMS paradigm, Figure 4-9 shows the total population of CD45+ cells, examining febuxostat treatment. In regard to total white blood cells, the chronic delivery of febuxostat did not result in any statistically significant differences, between the groups.

Figure 4-10 illustrates alterations in the respective T-cells and T-cell subsets with the chronic treatment of febuxostat in lean and obese mice exposed to UCMS. Overall, there were no statistically significant differences in total T-cells $\left(C D 3^{+}\right)$, Helper-T cells $\left(\mathrm{CD} 4^{+}\right)$, Cytotoxic-T cells $\left(\mathrm{CD} 8^{+}\right)$, or the $\mathrm{CD}^{+}$to $\mathrm{CD}^{+}$ratio (Figures $\left.4-10 \mathrm{~A}-4-10 \mathrm{D}\right)$ between groups.

B-cells are seen in Figure 4-11. Again, chronic febuxostat treatment did not have any significant effects on the CD45R $\mathrm{R}^{+}$populations between groups.

Figure 4-12 shows macrophage subsets. Chronic febuxostat treatment did not lead to any significant alterations in the M1 phenotype (Fig. 4-12A), the M2 phenotype (Fig. 412B), or the M1 to M2 ratio (Fig. 4-12C) between groups. 




Figure 4-9: Percentage of white blood cells $\left(C D 45^{+}\right)$in lean and obese animals with UCMS and febuxostat treatment (UCMS+Feb). $n=4-5$ per group.
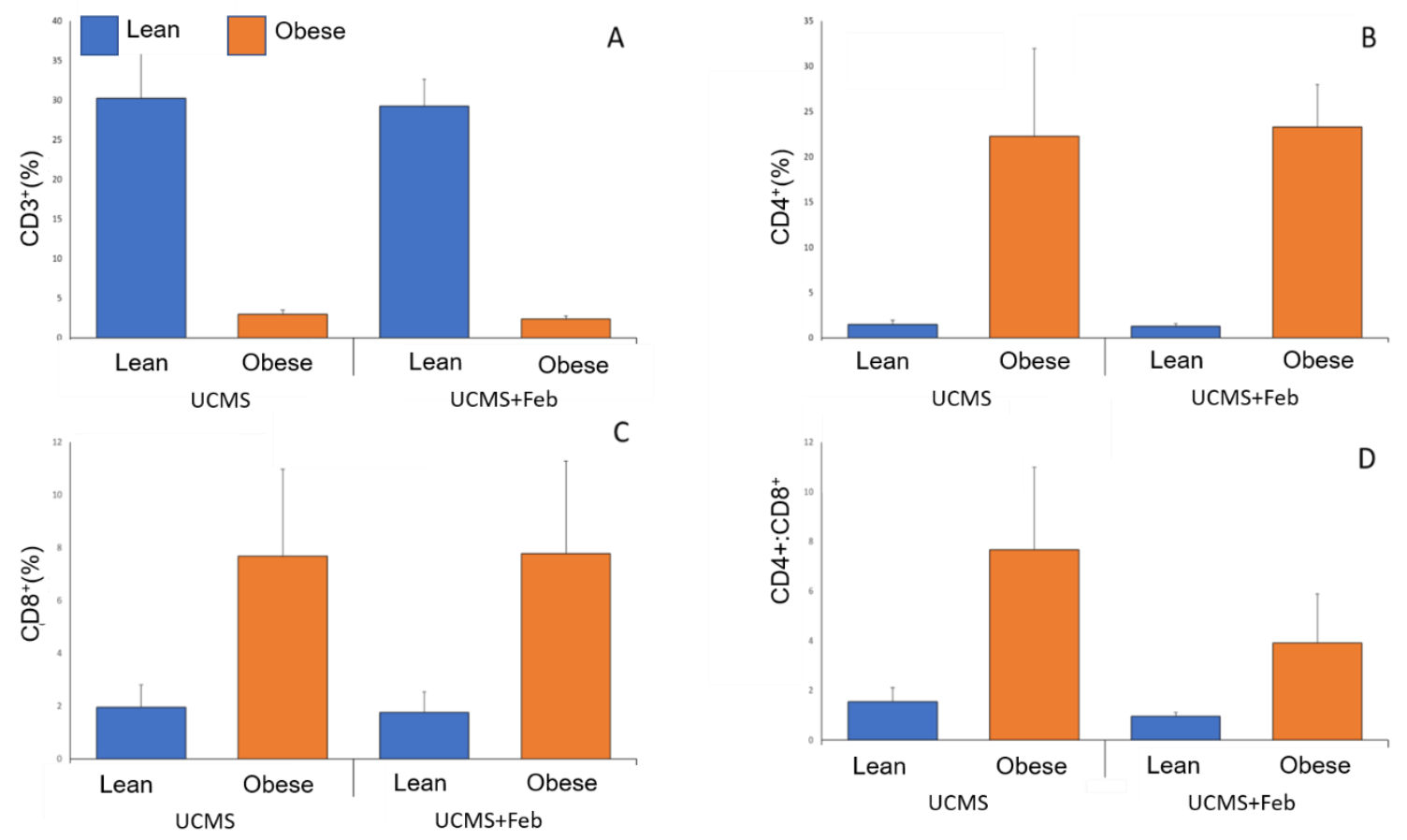

Figure 4-10: Percentage of A) T-cells $\left(C D 3^{+}\right)$, B) Helper-T cells (CD4+), C) Cytotoxic-T cells $\left(\mathrm{CD} 8^{+}\right)$, and $\left.\mathrm{D}\right)$ the $\mathrm{CD} 4^{+}$to $\mathrm{CD} 8^{+}$ratio (an indicator of inflammation) in lean and obese animals with UCMS and febuxostat treatment (UCMS+Feb). $n=4-5$ per group. 


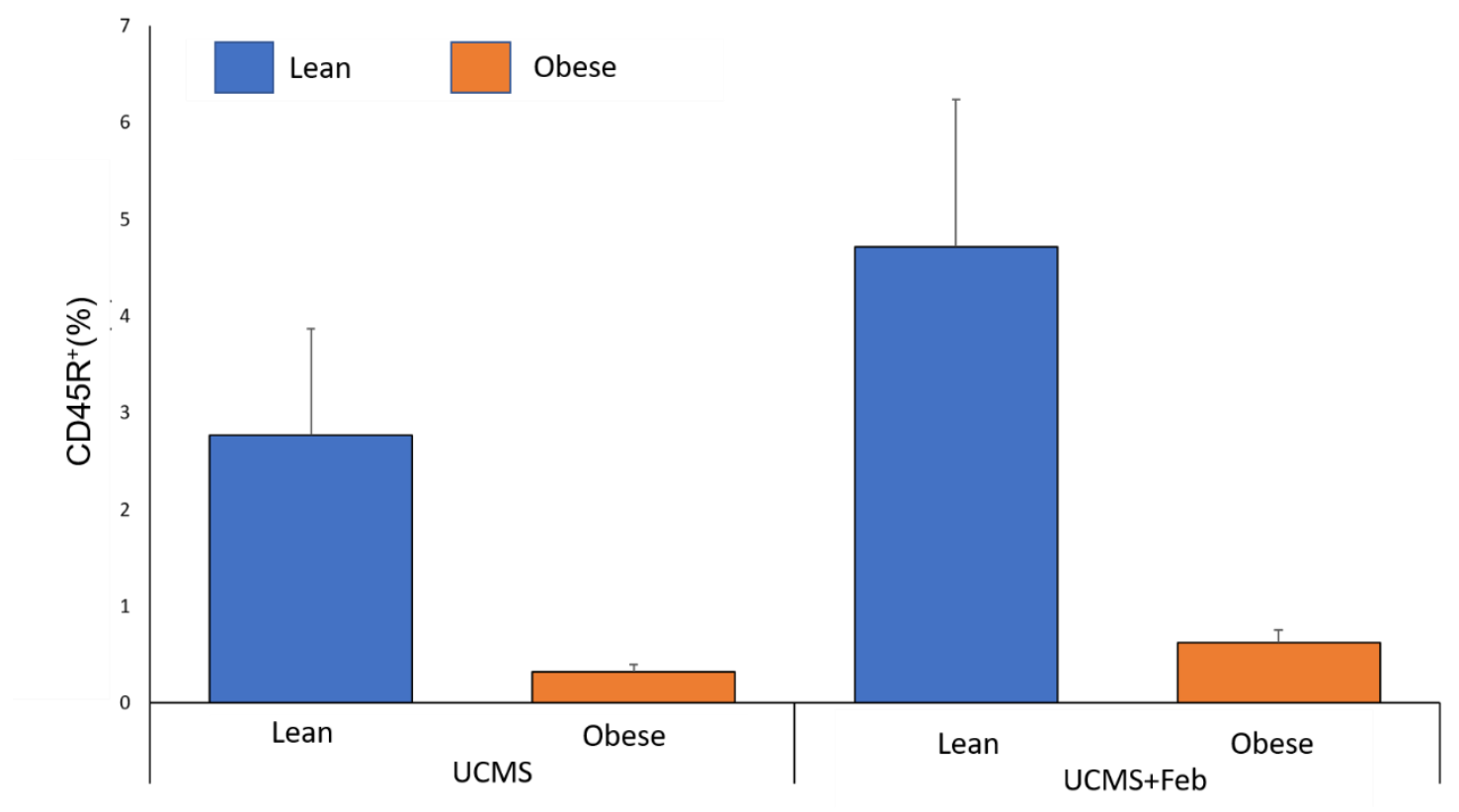

Figure 4-11: Percentage of B-cells $\left(C D 45 R^{+}\right)$in lean and obese animals with UCMS and febuxostat treatment (UCMS+Feb). $n=4-5$ per group.
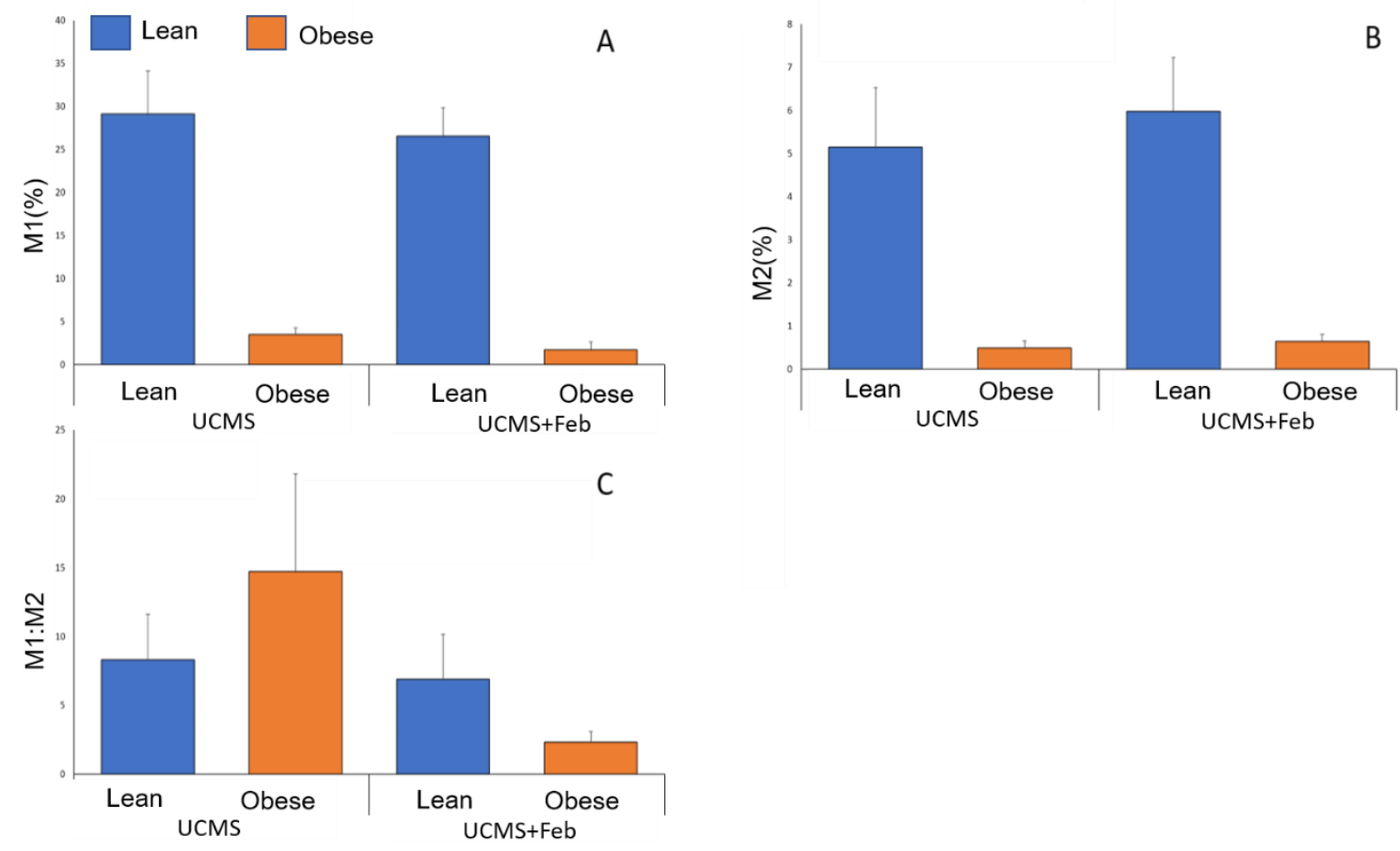

Figure 4-12: Percentage of A) M1 macrophages, B) M2 macrophages, C) the M1/M2 ratio (an indicator of inflammation) in lean and obese animals with UCMS and febuxostat treatment (UCMS+Feb). $n=4-5$ per group. 


\section{Chapter 5}

\section{Discussion}




\subsection{Alterations to Immune Cell Populations}

The primary purpose of this study was to assess alterations in neuroimmune cell populations, as a result of obesity, chronic stress, and a combination of the two. Furthermore, the study aimed to gauge if febuxostat, an inhibitor of xanthine oxidase, would attenuate any negative alterations. Consistent with our hypothesis, we observed an alteration to immune cell populations in response to chronic stress delivery, in some cases. However, contrary to our hypothesis, we did not find a consistent pro-inflammatory response with obesity, and observed minimal involvement from febuxostat.

Previous work has shown that obesity leads to a constant state of systemic inflammation, indicating an absolute increase in white blood cells. ${ }^{106}$ Adipose tissue serves as a reservoir for activated immune cells, with macrophages being one of the most populous cell types. In a pro-inflammatory environment, the M1 phenotype of macrophages has a higher prevalence than the generally anti-inflammatory M2. In terms of cytokine secretion, M1 macrophages are notorious for releasing messengers including TNF- $\alpha$ and IL-6, causing inflammation and recruitment of additional immune cells. ${ }^{42,43}$ To a lesser degree, M2 macrophages contribute to inflammation due to their (albeit, lower) expression of MHC II. This extracellular immune complex allows for the presentation of a pathogenic antigen to a CD4+ -cell and leads to its activation. ${ }^{56}$ In the study at hand, diet-induced obesity did not produce the expected results, based on the understanding of the physiological consequences of obesity. Beginning with total white blood cells, the obese phenotype did not result in the significant increase that was expected. In the context of microglia, obesity did not lead to the expected increase in the M1 phenotype, though it did result in a significant decrease in the anti-inflammatory M2 phenotype. 
However, this did not translate to the M1:M2 ratio. As microglia present antigens, activating $\mathrm{CD} 4{ }^{+} \mathrm{T}$-cells, additional immune cells become activated; active $\mathrm{CD} 4^{+} \mathrm{T}$-cells secrete IFN- - , acting in a positive feedback loop, increasing macrophage recruitment. ${ }^{56}$ Additionally, CD4 ${ }^{+} \mathrm{T}$-cells induce the activation and proliferation of both $\mathrm{CD} 8^{+} \mathrm{T}$-cells and B-cells, further contributing to the systemic inflammation. ${ }^{42,52}$ As such, it was expected that there would be an overall increase in T-cells, T-cell subsets, and B-cells and a decrease in the $\mathrm{CD} 4^{+}$to $\mathrm{CD} 8^{+}$ratio. The ratio of $\mathrm{CD} 4^{+}$to $\mathrm{CD} 8^{+}$cells is used as a general reference point for immune system activation, with normal values considered to be 1.52.5; an intense immune response would result in $C D 8^{+}$T-cell proliferation, causing an inversion of the ratio. ${ }^{105,106,108}$ The data did not entirely align with what would be expected; there was an overall decrease in T-cells, though there were greater percentages staining $\mathrm{CD}^{+}$and (independently) $\mathrm{CD}^{+}$. There were no significant differences in the T-cell ratio, and unexpectedly, B-cell quantity decreased. Overall, the acquisition of the obese phenotype did not result in much of a significant difference, compared to controls. This conclusion is also true for lean and obese animals that were given febuxostat in their drinking water; the xanthine oxidase inhibitor did not seem to significantly affect the obese cohort.

The implementation of the unpredictable chronic mild stress protocol sought to deliver a chronic stress component. Bouts of stress activate the HPA axis, which leads to the downstream secretion of glucocorticoids. While the mechanism is a negative feedback loop that is programmed to turn itself off, chronic stress overloads the system and can lead to tangential, adverse immune effects. For example, the system has the potential of overexpressing cortisol, causing immunosuppression. Conversely, another 
fate is hypocortisolism, preventing immunosuppression. While cortisol levels were not assessed, two pieces of evidence that provide support for the theory of hypocortisolism: a significant decrease in total white blood cells in the obese UCMS population, compared to the lean UCMS group, and a significant decrease in M2 macrophages. Though they were statistically significant, these data are not sufficient to fully explain what is happening in the system. Cortisol values were not measured for this study and there were no other significant cell population alterations. Similar studies that have used the UCMS protocol have reported data both on cellular alterations, as well as changes in cytokines. For example, Chiang et al. found pro-inflammatory cytokines pre- vs. post-stress protocol, show a positive relationship between stress and inflammation. ${ }^{109}$ Additional reviews detailed a correlation between stress, immunosuppression, and the neuroimmune profile, such as activated microglia recruit peripheral T-cells to the central nervous system, creating an exacerbated pro-inflammatory environment, resulting in harm to the host. ${ }^{110,111}$

Due to the lack of evidence that a pro-inflammatory environment was established with obesity in our study, our ability to interpret the effectiveness of chronic febuxostat delivery as a therapy to combat inflammation is limited.

Under normal circumstances, xanthine oxidase catalyzes the reaction of hypoxanthine to uric acid - the primary problem with this is the downstream production of ROS. An increase in ROS leads to a reduction in available NO.; , and greater potential to sustain tissue injury. ${ }^{126}$ This additionally exacerbates the pro-inflammatory response, happening concurrently in the stressed system. This chronic occurrence leads to a decline in vascular function, in the form of dilatory impairment. ${ }^{78,126}$ Although, the use of 
febuxostat has been challenged - while it has been shown to be successful in inhibiting $\mathrm{XO}$, febuxostat has demonstrated an inability to cross the blood brain barrier, mitigating the compound's ability to be especially successful at reducing oxidative stress in the central nervous system. ${ }^{125}$ However, instances of intense stress can compromise the integrity of the blood brain barrier;. Previous studies have determined the reduced function of the blood brain barrier can allow for larger molecules, including proinflammatory cytokines, to cross. ${ }^{112,113,114}$

\subsection{Confounding Factors}

Body mass and assessment of coat scores were conducted to provide both qualitative and quantitative assessment of the exposure model/conditions. Based on the significant difference in body mass and coat score between the experimental groups, it is safe to say that the exposure was successfully implemented. However, conducting the flow cytometry protocol was met with several experimental challenges.

Flow cytometry itself was done in an unconventional way, to accommodate concurrent project aspects. Flow cytometry-centric projects usually aim to keep the number of surgery days to a minimum - having the number of trials in the study be spread over the course of 6 weeks made for a huge challenge by itself, as data for flow cytometry is acquired by 1) homogenizing and staining the cells, 2) incubating for a 12-hour minimum to allow for plasma membrane fixation/up to 2 weeks, 3) running the samples on the LSRFortessa, 4) creating a gating strategy to discern cell populations, and 5) developing plots to determine the percentage of each cell type. 
Flow cytometry consists of mostly basic steps, but is lengthy, utilizes multiple incubation periods, and requires full attention. In addition to this, certain steps, such as adding the percoll underlay, required a great deal of practice to properly execute. Inconsistencies occurred due to the limited use of equipment due to conflicting time schedules. This conflict was most exaggerated with running the samples, as some were run as early as possible, while others had to wait the full two weeks. This impacts the size of the cells, and can cause the LSRFortessa to inaccurately classify certain cells. In this study, given the time invested in the exposure protocol, we sought to differentiate using 9 fluorescently-labeled antibodies to gain the most information possible. However, having this quantity increased the difficulty of data acquisition and subsequent analysis. Flow cytometry also involves a degree of bias, as there are somewhat less-defined setpoints on the exact spot to put gates on single-stain controls, with a similar problem occurring during gate analysis. Due to all of this, the original schema of 6 animals per group dwindled to 4-5 per group, with inconsistencies being prevalent throughout them. If surgery days were minimized to focus on this immune aspect, the consistency of the end products would likely be more similar, as well. In addition to flow cytometry, utilizing complementary methodologies would create a more comprehensive picture. Intracellular staining could be used to expand on the flow cytometry method, allowing for data collection of cytokines. In addition, integrating a methodology such as an ELISA or immunohistochemistry could be done. Either of these protocols could be used to verify the presence of pro- and anti-inflammatory cytokines, confirming cellular actions at the molecular level. 


\subsection{Limitations}

The examination of the pro-inflammatory milieu requires a complex approach. Utilizing flow cytometry as a means of identifying cell populations was an appropriate first step to uncovering the cellular adaptations. With that being said, successful completion of the protocol is dependent on the skilled execution of many crucial and meticulous steps - due to the high potential of error, one of the limitations was having a relatively low sample size, that became even lower in some groups due to errors. In addition, the protocol implementation was not ideal, as it is more common to process all of the animals for flow cytometry in one day, in contrary to this 6-week approach.

We only evaluated flow cytometry for this study. While this aids in identifying cell populations and can help to establish comparisons between controls and stressors, the types of cells themselves do not totally define what the systemic physiology looks like, as we have not looked at the concentration of pro- and anti-inflammatory cytokines, or determined whether or not the mice showed any other signs of systemic dysfunction. The aim was to highlight a shift to a pro-inflammatory cellular profile, and later distinguish evaluate cytokines.

\subsection{Future Research}

In this study, the only methodological approach used was flow cytometry as a means of discerning general cell populations. This methodology can be expanded on because the phenotype of macrophages is so crucial to their function, isolating enough brain immune cells could help to parse out M1 and M2 macrophages in the brain, instead of just having a wholistic picture. 
This same concern also applies to the adaptive immune system assessment of Tcells. The current approach for determining pro- vs anti-inflammatory involves determining the $\mathrm{CD} 4^{+}$to $\mathrm{CD} 8^{+}$ratio. While it is a noted approach, using this ratio may not necessarily be the most ideal due to gauge the inflammatory status as both have previously been shown to increase with stress. However, a subset of CD4+ $\mathrm{T}$-cells, known as regulatory T-cells, show a more direct correlation with the inflammatory status of the environment.

In addition to the surface staining protocol, it would also be informative to employ intracellular staining. This is a subset of flow cytometry that involves permeabilizing the plasma membrane to allow the infiltration of antibodies. This provides a more in-depth look at the actions of the cells, as cytokines are able to be identified and quantified. As an additional alternative, the use of protocols such as immunohistochemistry can be utilized to discover the cytokines at hand.

Because febuxostat acts as an antagonist to a pathway that ultimately results in the production of superoxides, it would be wise to measure any alterations in that activity. Superoxides have the potential to damage the vasculature, and are upregulated with stress - monitoring alterations in their production could give insight into the functionality of chronic febuxostat delivery.

Another component to add is the inclusion of female mice. Sex-associated immunological differences are primarily resultant from the respective quantities of sex hormones. Estrogen has been shown to be influential in immune cell mediation, including pathways that affect activation, differentiation, and apoptosis. ${ }^{115}$ In estrogen receptor 
knockout models, the development of the thymus was stunted, which would be especially impactful on the development and function of T-cells. ${ }^{116}$

Immune cells have been shown to express estrogen receptor mRNA, indicating a link to the sex hormone as an effector molecule on a variety of cell types. ${ }^{120}$ This is further supported Escribese et al., whilst examining Dendritic Cells, a pivotal link between the Innate and Adaptive Immune Systems. ${ }^{119}$ While normally a part of the process to active CD4 + T-cells, Dendritic Cells that were isolated from a system that was primed with estrogen were shown to have a reduced functional capacity, indicating a suppressive role by the hormone.

The priming of the immune system may be necessary to combat pathogenic threats, but overstimulation may lead to autoimmune consequences. Mor et al. demonstrated the complexity of such consequences, showing that receptor isoforms are critical. ${ }^{117}$ A potential outcome, mediated by estrogen, is the delaying of monocyte apoptosis, leading to the presentation of symptoms of an autoimmune disease. ${ }^{117}$ Similar to monocytes, B- cells have also been shown to exhibit a more robust phenotype, supporting estrogen's potential to be both anti-apoptotic and pro-inflammatory. ${ }^{118}$ 


\section{Chapter 6}

\section{Conclusion}




\subsection{Conclusion}

In conclusion, the study is suggestive that the implementation of stressors has an impact on the immune system, with significant differences in white blood cells and M2 macrophages seen. Although cell populations were assessed, the baseline expectation of obesity causing a pro-inflammatory environment was not met. While psychological stress lead to a significant decrease in M2 macrophages, overall, the data did not support the validate that chronic stress and obesity caused a drastic alteration of the systemic homeostasis. Additionally, the chronic delivery of febuxostat did not result in significant change, though this interpretation is hampered due to the lack of evidence showing an increase in the pro-inflammatory state induced by chronic stress or obesity. 


\section{References}

1. Ng, M., Fleming, T., Robinson, M., Thomson, B., Graetz, N., Margono, C., . . . Abera, S. (2014). Global, regional, and national prevalence of overweight and obesity in children and adults during 1980-2013: A systematic analysis for the global burden of disease study 2013. The Lancet, 384(9945), 766-781.

2. Ogden, C., Carroll, M., Kit, B., \& Flegal, K. (2014). Prevalence of childhood and adult obesity in the united states, 2011-2012. Jama - Journal of the American Medical Association, 311(8), 806-814. doi:10.1001/jama.2014.732

3. Orchard, T., Temprosa, M., Goldberg, R., Haffner, S., Ratner, R., Marcovina, S., . .. Diabetes Prevention Program Research Group. (2005). The effect of metformin and intensive lifestyle intervention on the metabolic syndrome: The diabetes prevention program randomized trial. Annals of Internal Medicine, 142(8), 611-9.

4. Ellulu, M., Abed, Y., Rahmat, A., Ranneh, Y., \& Ali, F. (2014). Epidemiology of obesity in developing countries: Challenges and prevention. Global Epidemic Obesity, 2(1), 2-2. doi:10.7243/2052-5966-2-2

5. Smith, K., \& Smith, M., Department of Orthopedics and Rehabilitation, University of Florida, 3450 Hull Road, Gainesville, FL 32611, USA. (2016). Obesity statistics. Primary Care: Clinics in Office Practice, 43(1), 121-135. doi:10.1016/j.pop.2015.10.001

6. Flegal, K., Kit, B., Orpana, H., \& Graubard, B. (2013). Association of all-cause mortality with overweight and obesity using standard body mass index categories: A systematic review and meta-analysis. Jama, 309(1), 71-82. doi:10.1001/jama.2012.113905 
7. Berrington, D., Hartge, P., Cerhan, J., Flint, A., Hannan, L., Maclnnis, R., . . Thun, M. (2010). Body-mass index and mortality among 1.46 million white adults. The New England Journal of Medicine, 363(23), 2211-9. doi:10.1056/NEJMoa1000367

8. Janssen, I. (2007). Morbidity and mortality risk associated with an overweight bmi in older men and women. Obesity, 15(7), 1827-1840. doi:10.1038/oby.2007.217

9. Ardern, C., Katzmarzyk, P., Janssen, I., \& Ross, R. (2003). Discrimination of health risk by combined body mass index and waist circumference. Obesity Research, 11(1), 135-142. doi:10.1038/oby.2003.22

10. Flegal, K., Graubard, B., Williamson, D., \& Gail, M. (2008). Cause-specific excess deaths associated with underweight, overweight, and obesity. Obstetrical \& Gynecological Survey, 63(3), 157-159. doi:10.1097/01.ogx.0000305202.93507.2a

11. Weisberg, S., McCann, D., Desai, M., Rosenbaum, M., Leibel, R., \& Ferrante, A. (2003). Obesity is associated with macrophage accumulation in adipose tissue. The Journal of Clinical Investigation, 112(12), 1796-808.

12. Lumeng, C., Bodzin, J., \& Saltiel, A. (2007). Obesity induces a phenotypic switch in adipose tissue macrophage polarization. The Journal of Clinical Investigation, 117(1), 175-84.

13. Skinner, A., Armstrong, S., Ravanbakht, S., Perrin, E., \& Skelton, J. (2018). Prevalence of obesity and severe obesity in us children, 19992016. Pediatrics, 141(3). doi:10.1542/peds.2017-3459

14. Obesity trends in the united states. (2016). Journal of the National Cancer Institute, 108(10). 
15. Betteridge, D. (2000). What is oxidative stress? Metabolism: Clinical and Experimental, 49(2), 3-8.

16. Wolin, K., \& Petrelli, J. (2009). Obesity (Biographies of disease series). Santa Barbara, Calif.: Greenwood Press. (2009).

17. Meldrum, D., M.D., Morris, M., M.Ed., R.D., C.D.E., \& Gambone, J., D.O., M.P.H. (2017). Obesity pandemic: Causes, consequences, and solutions—but do we have the will? Fertility and Sterility, 107(4), 833-839. doi:10.1016/j.fertnstert.2017.02.104

18. Freedman, D., \& Berenson, G. (2017). Tracking of bmi z scores for severe obesity. Pediatrics, 140(3). doi:10.1542/peds.2017-1072

19. Wetzels, S., Bijnen, M., Schalkwijk, C., Wouters, K., Wijnands, E., \& Biessen, E. (2018). Characterization of immune cells in human adipose tissue by using flow cytometry. Journal of Visualized Experiments, 2018(133). doi:10.3791/57319

20. Medrikova, D., Sijmonsma, T., Sowodniok, K., Richards, D., Delacher, M., Sticht, C., ... Herzig, S. (2015). Brown adipose tissue harbors a distinct sub-population of regulatory t cells. Plos One, 10(2), 0118534. doi:10.1371/journal.pone.0118534

21. Liu, R., \& Nikolajczyk, B. (2019). Tissue immune cells fuel obesity-associated inflammation in adipose tissue and beyond. Frontiers in Immunology, 10, 15871587. doi:10.3389/fimmu.2019.01587

22. Lumeng, C., Bodzin, J., \& Saltiel, A. (2007). Obesity induces a phenotypic switch in adipose tissue macrophage polarization. The Journal of Clinical Investigation, 117(1), 175-84. 
23. Belmaker, R., \& Agam, G. (2008). Major depressive disorder. New England Journal of Medicine, 358(1), 55-68. doi:10.1056/NEJMra073096

24. Mezuk, B., Eaton, W., Albrecht, S., \& Golden, S. (2008). Depression and type 2 diabetes over the lifespan: A meta-analysis. Diabetes Care, 31(12), 2383-90. doi:10.2337/dc08-0985

25. Wirtz, P., \& Von Känel, R. (2017). Psychological stress, inflammation, and coronary heart disease. Current Cardiology Reports, 19(11), 1-10.

26. Hänsel, A., Hong, S., Cámara, R., \& Von Känel, R. (2010). Inflammation as a psychophysiological biomarker in chronic psychosocial stress. Neuroscience and Biobehavioral Reviews, 35(1), 115-121. doi:10.1016/j.neubiorev.2009.12.012

27. Wirtz, P., Von, K., Schnorpfeil, P., Ehlert, U., Frey, K., \& Fischer, J. (2003). Reduced glucocorticoid sensitivity of monocyte interleukin-6 production in male industrial employees who are vitally exhausted. Psychosomatic Medicine, 65(4), $672-8$.

28. Ridker, P. (2016). From c-reactive protein to interleukin-6 to interleukin-1: Moving upstream to identify novel targets for atheroprotection. Circulation Research, 118( 1), 145-56. doi:10.1161/CIRCRESAHA.115.306656

29. Kaptoge, S., Seshasai, S., Gao, P., Freitag, D., Butterworth, A., Borglykke, A., . . . Danesh, J. (2014). Inflammatory cytokines and risk of coronary heart disease: New prospective study and updated meta-analysis. European Heart Journal, 35(9), 578-89. doi:10.1093/eurheartj/eht367

30. Passos, I., Vasconcelos-Moreno, M., Costa, L., Kunz, M., Brietzke, E., Quevedo, J., . . Kauer-Sant'Anna, M. (2015). Inflammatory markers in post-traumatic stress 
disorder: A systematic review, meta-analysis, and meta-regression. The Lancet. Psychiatry, 2(11), 1002-12. doi:10.1016/S2215-0366(15)00309-0

31. Jung, U., \& Choi, M. (2014). Obesity and its metabolic complications: The role of adipokines and the relationship between obesity, inflammation, insulin resistance, dyslipidemia and nonalcoholic fatty liver disease. International Journal of Molecular Sciences, 15(4), 6184-223. doi:10.3390/ijms15046184

32. Khoo, N., Csanyi, G., Bonacci, G., Freeman, B., Kelley, E., \& Orlando FL USA 20101117-20101121. (2010). Obesity-induced endothelial dysfunction and vascular oxidative stress: Contributions of xanthine oxidase. Free Radical Biology and Medicine, 49, 39. doi:10.1016/j.freeradbiomed.2010.10.078

33. Salim, S., Asghar, M., Chugh, G., Taneja, M., Xia, Z., \& Saha, K. (2010). Oxidative stress: A potential recipe for anxiety, hypertension and insulin resistance. Brain Research, 1359(C), 178-185. doi:10.1016/j.brainres.2010.08.093

34. Nomura, J., Busso, N., Ives, A., Matsui, C., Tsujimoto, S., Shirakura, T., . . . Yamanaka, Y. (2015). Xanthine oxidase inhibition by febuxostat attenuates experimental atherosclerosis in mice. Scientific Reports, 4(1). doi:10.1038/srep04554

35. Yisireyili, M., Hayashi, M., Wu, H., Uchida, Y., Yamamoto, K., Kikuchi, R., .. . Tak eshita, K. (2017). Xanthine oxidase inhibition by febuxostat attenuates stress-indu ced hyperuricemia, glucose dysmetabolism, and prothrombotic state in mice. Scie ntific Reports, 7(1), 1266-1266. doi:10.1038/s41598-017-01366-3 
36. Yoshizumi, M., Perrella, M., Burnett, J., \& Lee, M. (1993). Tumor necrosis factor d ownregulates an endothelial NO synthase mrna by shortening its half-life. Circulat ion Research, 73(1), 205-9.

37. Aljada, A., Ghanim, H., Assian, E., \& Dandona, P. (2002). Tumor necrosis factor-[ alpha ] inhibits insulin-induced increase in endothelial NO synthase and reduces $\mathrm{i}$ nsulin receptor content and phosphorylation in human aortic endothelial cells. Me tabolism, 51(4) 487-491. doi:10.1053/meta.2002.31339

38. Dandona, P., Aljada, A., \& Bandyopadhyay, A. (2004). Inflammation: The link bet ween insulin resistance, obesity and diabetes. Trends in Immunology, 25(1), 4-7.

39. McTigue, K., Larson, J., Valoski, A., Burke, G., Kotchen, J., Lewis, C., . . Kuller, L. (2006). Mortality and cardiac and vascular outcomes in extremely obese wome n. Jama, 296(1), 79-86.

40. Vainchtein, I. (2018). Astrocyte-derived interleukin-33 promotes microglial synaps e engulfment and neural circuit development. Science, 6381, 1269-1273.

41. Medcom (Producer), \& . (2009). Overview of anatomy and function: The innate im mune system. [Video/DVD] Medcom. Retrieved from https://video-alexanderstree t-com.www.libproxy.wvu.edu/watch/overview-of-anatomy-and-function-the-innate -immune-system

42. Weiss, G., \& Schaible, U. (2015). Macrophage defense mechanisms against intra cellular bacteria. Immunological Reviews. (2015).

43. Arango, D., \& Descoteaux, A. (2014). Macrophage cytokines: Involvement in imm unity and infectious diseases. Frontiers in Immunology, 5, 491-491. doi:10.3389/fi mmu.2014.00491 
44. Amiram, E., Isabelle, E., Patrizia, E., Jerrold, S., \& Heiko, E. (2012). Macrophages in inflammation and its resolution. Frontiers in Immunology, (2012). doi:10.3389/fimmu.2012.00324

45. Felipe, M., Lucas, S., Isaias, G., \& Fernanda, M. (2019). Brain innate immune response in diet-induced obesity as a paradigm for metabolic influence on inflammatory signaling. Frontiers in Neuroscience, (2019). doi:10.3389/fnins.2019.00342

46. Spinas, E., Saggini, A., Kritas, S., Cerulli, G., Caraffa, A., Antinolfi, P., . . Conti, P. (2014). Obesity, inflammation and neurological alterations. European Journal of Inflammation, 12(3), 415-418. doi:10.1177/1721727X1401200302

47. Topham, N., \& Hewitt, E. (2009). Natural killer cell cytotoxicity: How do they pull the trigger? Immunology, 128(1), 7-15. doi:10.1111/j.1365-2567.2009.03123.x

48. Lenz, K., \& Nelson, L. (2018). Microglia and beyond: Innate immune cells as regulators of brain development and behavioral function. Frontiers in Immunology, 9, 698-698. doi:10.3389/fimmu.2018.00698

49. Galloway, D., Phillips, A., Owen, D., \& Moore, C. (2019). Phagocytosis in the brain: Homeostasis and disease. Frontiers in Immunology, 10, 790-790. doi:10.3389/fimmu.2019.00790

50. Ginhoux, F., Hoeffel, G., Low, D., Lim, S., \& Huber, T. (2013). Origin and differentiation of microglia. Frontiers in Cellular Neuroscience, Mar(Mar). doi:10.3389/fncel.2013.00045 
51. Paolicelli, R., Bolasco, G., Pagani, F., Maggi, L., Scianni, M., Panzanelli, P., . . . Gross, C. (2011). Synaptic pruning by microglia is necessary for normal brain development. Science, 333(6048), 1456-1458.

52. Den, H., Arens, R., \& Van, Z. (2014). The activation of the adaptive immune syste m: Cross-talk between antigen-presenting cells, t cells and b cells. Immunology $L$ etters, 162(2), 103-112. doi:10.1016/j.imlet.2014.10.011

53. Smolders, J., Remmerswaal, E., Schuurman, K., Melief, J., Van Eden, C., Van Lier, R., . . . Hamann, J. (2013). Characteristics of differentiated cd8 and cd4 t cells present in the human brain. Acta Neuropathologica : Pathology and Mechanisms of Neurological Disease, 126(4), 525-535. doi:10.1007/s00401013-1155-0

54. Xie, L., Choudhury, G., Winters, A., Yang, S., \& Jin, K. (2015). Cerebral regulatory tcells restrain microglia/macrophage-mediated inflammatory responses via il-10. European Journal of Immunology, 45(1), 180-91. doi:10.1002/eji.201444823

55. Kipnis, J., Mizrahi, T., Hauben, E., Shaked, I., Shevach, E., \& Schwartz, M. (2002). Neuroprotective autoimmunity: Naturally occurring cd4 cd25 regulatory t cells suppress the ability to withstand injury to the central nervous system. Proceedings of the National Academy of Sciences of the United States of America, 99(24), 15620-15625.

56. Zhang, S., Zhang, H., \& Zhao, J. (2009). The role of cd4 t cell help for cd8 ctl activation. Biochemical and Biophysical Research Communications, 384(4), 405-408. doi:10.1016/j.bbrc.2009.04.134 
57. Bevan, M. (2004). Helping the cd8( ) t-cell response. Nature Reviews. Immunology, 4(8), 595-602.

58. Alberts B, Johnson A, Lewis J, et al. Molecular Biology of the Cell. 4th edition. New York: Garland Science; 2002. Helper T Cells and Lymphocyte Activation. Available from: https://www.ncbi.nlm.nih.gov/books/NBK26827/

59. Guilliams, T, Edwards, L (2010) Chronic stress and the hpa axis: clinical assessment and therapeutic considerations, 9(2), 1-12

60. Joëls, M., \& Baram, T. (2009). The neuro-symphony of stress. Nature Reviews. Neuroscience, 10(6), 459-66. doi:10.1038/nrn2632

61. Scharf, S., \& Schmidt, M. (2012). Animal models of stress vulnerability and resilience in translational research. Current Psychiatry Reports, 14(2), 159-165. doi:10.1007/s11920-012-0256-0

62. Willner, P. (2005). Chronic mild stress (cms) revisited: Consistency and behavioural-neurobiological concordance in the effects of cms. Neuropsychobiology, 52(2), 90-110. doi:10.1159/000087097

63. Mineur, Y., Belzung, C., \& Crusio, W. (2006). Effects of unpredictable chronic mild stress on anxiety and depression-like behavior in mice. Behavioural Brain Research, 175(1), 43-50. doi:10.1016/j.bbr.2006.07.029

64. Koolhaas, J., Bartolomucci, A., Buwalda, B., Flügge, G., De Boer, S., Korte, S., . . . Fuchs, E. (2011). Stress revisited: A critical evaluation of the stress concept. Ne uroscience and Biobehavioral Reviews, 35(5), 1291-1301. 
65. Rice, C., Sandman, C., Lenjavi, M., \& Baram, T. (2008). A novel mouse model for acute and long-lasting consequences of early life stress. Endocrinology, 149(10), 4892-900. doi:10.1210/en.2008-0633

66. Emily, B., Kent, L., Nalini, S., \& Paul, D. (2018). Cerebrovascular dysfunction with stress and depression. Brain Circulation, 4(2), 43-53. doi:10.4103/bc.bc_6_18

67. Rosengren, A., Hawken, S., Ounpuu, S., Sliwa, K., Zubaid, M., Almahmeed, W., . .. INTERHEART investigators. (2004). Association of psychosocial risk factors wi th risk of acute myocardial infarction in 11119 cases and 13648 controls from $52 \mathrm{c}$ ountries (the interheart study): Case-control study. Lancet (london, England), 364 (9438), 953-62.

68. Phillips, A., \& Barr, A. (1997). Effects of chronic mild stress on motivation for sucr ose: Mixed messages. Psychopharmacology, 134(4), 361-362. doi:10.1007/s002 130050469

69. Frisbee, J., Brooks, S., Stanley, S., \& D'Audiffret, A. (2015). An unpredictable chr onic mild stress protocol for instigating depressive symptoms, behavioral changes and negative health outcomes in rodents. Journal of Visualized Experiments : Jov e, 106(106). doi:10.3791/53109

70. Natajaran, R., Forrester, L., Chiaia, M., Yamamoto, B. (2017) Chronic-stress-indu ced behavioral changes associated with subregion-selective serotonin cell death i $\mathrm{n}$ the dorsal raphe. The Journal of Neuroscience. 37(26), 6214-6223.

71. Sterlemann, V., Ganea, K., Liebl, C., Harbich, D., Alam, S., Holsboer, F., . . . Sch midt, M. (2008). Long-term behavioral and neuroendocrine alterations following c 
hronic social stress in mice: Implications for stress-related disorders. Hormones a nd Behavior, 53(2), 386-394. doi:10.1016/j.yhbeh.2007.11.001

72. Mommersteeg, P., Heijnen, C., Kavelaars, A., \& Van, D. (2008). The hpa-axis and immune function in burnout. Progress in Brain Research, 167, 281-5.

73. Heim, C., Ehlert, U., \& Hellhammer, D. (2000). The potential role of hypocortisolis $\mathrm{m}$ in the pathophysiology of stress-related bodily disorders. Psychoneuroendocrin ology, 25(1), 1-35. doi:10.1016/S0306-4530(99)00035-9

74. Kiecolt-Glaser, J., McGuire, L., Robles, T., \& Glaser, R. (2002). Psychoneuroimm unology and psychosomatic medicine: Back to the future. Psychosomatic Medicin e, 64(1), 15-28.

75. Cohen, S., Janicki-Deverts, D., Doyle, W., Miller, G., Frank, E., Rabin, B., \& Turn er, R. (2012). Chronic stress, glucocorticoid receptor resistance, inflammation, an d disease risk. Proceedings of the National Academy of Sciences of the United St ates of America, 109(16), 5995-5999.

76. Tsigos, C., \& Chrousos, G. (2002). Hypothalamic-pituitary-adrenal axis, neuroend ocrine factors and stress. Journal of Psychosomatic Research, 53(4), 865-871. do i:10.1016/S0022-3999(02)00429-4

77. Monaghan, P., \& Spencer, K. (2014). Stress and life history. Current Biology : Cb , 24(10), 408-12. doi:10.1016/j.cub.2014.04.017

78. Brooks, S., Brnayan, K., DeVallance, E., Skinner, R., Lemaster, K., Sheets, J., . . . Chantler, P. (2018). Psychological stress-induced cerebrovascular dysfunction: The role of metabolic syndrome and exercise. Experimental Physiology, 103(5), 7 61-776. doi:10.1113/EP086892 
79. Broadley, A., Korszun, A., Jones, C., \& Frenneaux, M. (2002). Arterial endothelial function is impaired in treated depression. Heart (british Cardiac Society), 88(5), 5 21-3.

80. Chapelot, D., \& Charlot, K. (2019). Physiology of energy homeostasis: Models, ac tors, challenges and the glucoadipostatic loop. Metabolism: Clinical and Experime ntal, 92, 11-25. doi:10.1016/j.metabol.2018.11.012

81. Pi-Sunyer, F. (2002). The obesity epidemic: Pathophysiology and consequences of obesity. Obesity Research, 10(S12), 97. doi:10.1038/oby.2002.202

82. Makki, K., Froguel, P., \& Wolowczuk, I. (2013). Adipose tissue in obesity-related i nflammation and insulin resistance: Cells, cytokines, and chemokines. Isrn Inflam mation, 2013, 139239-139239. doi:10.1155/2013/139239

83. Ouchi, N., Parker, J., Lugus, J., \& Walsh, K. (2011). Adipokines in inflammation a nd metabolic disease. Nature Reviews. Immunology, 11(2), 85-97. doi:10.1038/nr i2921

84. Vachharajani, V., \& Granger, D. (2009). Adipose tissue: A motor for the inflammat ion associated with obesity. lubmb Life, 61(4), 424-430. doi:10.1002/iub.169

85. Ye, J. (2013). Mechanisms of insulin resistance in obesity. Frontiers of Medicine i n China, 7(1), 14-24. doi:10.1007/s11684-013-0262-6

86. Gorden, P., Arakaki, R., Collier, E., \& Carpentier, J. (1989). Biosynthesis and reg ulation of the insulin receptor. The Yale Journal of Biology and Medicine, 62(5), 5 $21-31$. 
87. Han, J., \& Levings, M. (2013). Immune regulation in obesity-associated adipose i nflammation. Journal of Immunology (baltimore, Md. : 1950), 191(2), 527-32. doi: 10.4049/jimmunol.1301035

88. Weisberg, S., McCann, D., Desai, M., Rosenbaum, M., Leibel, R., \& Ferrante, A. ( 2003). Obesity is associated with macrophage accumulation in adipose tissue. Th e Journal of Clinical Investigation, 112(12), 1796-808.

89. Murano, I., Barbatelli, G., Parisani, V., Latini, C., Muzzonigro, G., Castellucci, M., \& Cinti, S. (2008). Dead adipocytes, detected as crown-like structures, are preval ent in visceral fat depots of genetically obese mice. Journal of Lipid Research, 49 (7), 1562-8. doi:10.1194/Jr.M800019-JLR200

90. Lumeng, C., Bodzin, J., \& Saltiel, A. (2007). Obesity induces a phenotypic switch in adipose tissue macrophage polarization. The Journal of Clinical Investigation, 1 $17(1), 175-84$

91. Stanley, T., Zanni, M., Johnsen, S., Rasheed, S., Makimura, H., Lee, H., . . Grin spoon, S. (2011). Tnf- $\alpha$ antagonism with etanercept decreases glucose and incre ases the proportion of high molecular weight adiponectin in obese subjects with $f$ eatures of the metabolic syndrome. The Journal of Clinical Endocrinology \& Meta bolism, 96(1), 150. doi:10.1210/jc.2010-1170

92. Piya, M., McTernan, P., \& Kumar, S. (2013). Adipokine inflammation and insulin r esistance: The role of glucose, lipids and endotoxin. The Journal of Endocrinolog $y, 216(1), 15$. doi:10.1530/JOE-12-0498 
93. Stern, J., Rutkowski, J., \& Scherer, P. (2016). Adiponectin, leptin, and fatty acids i $\mathrm{n}$ the maintenance of metabolic homeostasis through adipose tissue crosstalk. $C$ ell Metabolism, 23(5), 770-784. doi:10.1016/j.cmet.2016.04.011

94. Forny-Germano, L., De, F., \& Do, N. (2019). The role of leptin and adiponectin in obesity-associated cognitive decline and alzheimer's disease. Frontiers in Neuros cience, 13(Jan). doi:10.3389/fnins.2018.01027

95. Yadav, A., Kataria, M., Saini, V., \& Yadav, A. (2013). Role of leptin and adiponect in in insulin resistance. Clinica Chimica Acta, 417, 80-84. doi:10.1016/j.cca.2012. 12.007

96. Staiger, H., \& Häring, H. (2005). Adipocytokines: Fat-derived humoral mediators 0 f metabolic homeostasis. Exp Clin Endocrinol Diabetes, 113(2), 67-79. doi:10.105 5/s-2004-830555

97. Berthoud, H. (2006). Homeostatic and non-homeostatic pathways involved in the control of food intake and energy balance. Obesity, 14(5), 197.

98. Lee, B., \& Shao, J. (2014). Adiponectin and energy homeostasis. Reviews in End ocrine and Metabolic Disorders, 15(2), 149-156.

99. Richard, D. (2015). Cognitive and autonomic determinants of energy homeostasis in obesity. Nature Reviews. Endocrinology, 11(8), 489-501. doi:10.1038/nrendo.2 015.103

100. Kadowaki, T., Yamauchi, T., Kubota, N., Hara, K., Ueki, K., \& Tobe, K. (2006). Ad iponectin and adiponectin receptors in insulin resistance, diabetes, and the metab olic syndrome. The Journal of Clinical Investigation, 116(7), 1784-92. 
101. Park, S., Kim, D., Kwon, D., \& Yang, H. (2011). Long-term central infusion of adip onectin improves energy and glucose homeostasis by decreasing fat storage and suppressing hepatic gluconeogenesis without changing food intake: Intracerebrov entricular adiponectin and glucose homeostasis. Journal of Neuroendocrinology, 2 3(8), 687-698. doi:10.1111/j.1365-2826.2011.02165.x

102. Police, S., Thatcher, S., Charnigo, R., Daugherty, A., \& Cassis, L. (2009). Obesity promotes inflammation in periaortic adipose tissue and angiotensin ii-induced abd ominal aortic aneurysm formation. Arteriosclerosis Thrombosis and Vascular Biol ogy, 29(10), 1458-1464.

103. Heriberto, R., Luis, E., Gabriela, R., \& Miguel, A. (2013). Obesity and inflammatio $\mathrm{n}$ : Epidemiology, risk factors, and markers of inflammation. International Journal o f Endocrinology, (2013). doi:10.1155/2013/678159

104. Qi, Y., Nie, Z., Lee, Y., Singhal, N., Scherer, P., Lazar, M., \& Ahima, R. (2006). Lo ss of resistin improves glucose homeostasis in leptin deficiency. Diabetes, 55(11) , 3083-90.

105. Howard, R., Fasano, C., Frey, L., \& Miller, C. (1996). Reference intervals of cd3, $\mathrm{cd} 4, \mathrm{~cd} 8, \mathrm{~cd} 4 / \mathrm{cd} 8$, and absolute cd4 values in asian and non-asian populations. Cytometry, 26(3), 231-232. doi:10.1002/(SICI)10970320(19960915)26:33.0.CO;2-H

106. Amadori, A., Zamarchi, R., De, S., Forza, G., Cavatton, G., Danieli, G., . . Chiec o-Bianchi, L. (1995). Genetic control of the cd4/cd8 t-cell ratio in humans. Nature Medicine, 1(12), 1279-83. 
107. Buckman, L., Hasty, A., Flaherty, D., Buckman, C., Thompson, M., Matlock, B., . . . Ellacott, K. (2014). Obesity induced by a high-fat diet is associated with increase d immune cell entry into the central nervous system. Brain, Behavior, and Immuni ty, 35, 33-42. doi:10.1016/j.bbi.2013.06.007

108. Frick, L., Arcos, M., Rapanelli, M., Zappia, M., Brocco, M., Mongini, C., . . Crema schi, G. (2009). Chronic restraint stress impairs t-cell immunity and promotes tum or progression in mice. Stress (amsterdam, Netherlands), 12(2), 134-43. doi:10.1 080/10253890802137437

109. Chiang, J., Eisenberger, N., Seeman, T., \& Taylor, S. (2012). Negative and comp etitive social interactions are related to heightened proinflammatory cytokine activ ity. Proceedings of the National Academy of Sciences of the United States of Am erica, 109(6), 1878-1882.

110. Karagkouni, A., Alevizos, M., \& Theoharides, T. (2013). Effect of stress on brain i nflammation and multiple sclerosis. Autoimmunity Reviews, 12(10), 947-953. doi: 10.1016/j.autrev.2013.02.006

111. Friese, M., \& Fugger, L. (2007). T cells and microglia as drivers of multiple sclero sis pathology. Brain : A Journal of Neurology, 130, 2755-7.

112. Banks, W.A. (2005). Blood-brain barrier transport of cytokines: a mechanism for $n$ europathology. Curr Pharm Des 11, 973-984.

113. Banks, W.A., Kastin, A.J., and Durham, D.A. (1989). Bidirectional transport of inte rleukin-1 alpha across the blood-brain barrier. Brain Res Bull 23, 433-437.

114. Banks, W.A., Ortiz, L., Plotkin, S.R., and Kastin, A.J. (1991). Human interleukin (I L) 1 alpha, murine IL-1 alpha and murine IL-1 beta are transported from blood to 
brain in the mouse by a shared saturable mechanism. J Pharmacol Exp Ther 259 , 988-996.

115. Kovats, S. (2015). Estrogen receptors regulate innate immune cells and signaling pathways. Cellular Immunology, 294(2), 63-9. doi:10.1016/j.cellimm.2015.01.018

116. Lambert, K., Curran, E., Judy, B., Lubahn, D., \& Estes, D. (2004). Estrogen recep tor-alpha deficiency promotes increased tnf-alpha secretion and bacterial killing $b$ y murine macrophages in response to microbial stimuli in vitro. Journal of Leukoc yte Biology, 75(6), 1166-72.

117. Mor, G., Sapi, E., Abrahams, V., Rutherford, T., Song, J., Hao, X., . . Kohen, F. ( 2003). Cellular immunology and immune regulation - interaction of the estrogen $r$ eceptors with the fas ligand promoter in human monocytes. The Journal of Immun ology : Official Journal of the American Association of Immunologists, 170(1), 114

118. Grimaldi, C., Cleary, J., Dagtas, A., Moussai, D., \& Diamond, B. (2002). Estrogen alters thresholds for b cell apoptosis and activation. The Journal of Clinical Investi gation, 109(12), 1625-33.

119. Escribese, M., Rodríguez-García, M., Sperling, R., Engel, S., Gallart, T., \& Moran , T. (2011). Alpha-defensins 1-3 release by dendritic cells is reduced by estrogen . Reproductive Biology and Endocrinology, 9(1), 118-118. doi:10.1186/1477-7827 $-9-118$

120. Phiel, K., Henderson, R., Adelman, S., \& Elloso, M. (2005). Differential estrogen r eceptor gene expression in human peripheral blood mononuclear cell population s. Immunology Letters, 97(1), 107-113. doi:10.1016/j.imlet.2004.10.007 
121. Banerjee, A., Mandal, A., Chanda, D., \& Chakraborti, S. (2003). Oxidant, antioxid ant and physical exercise. Molecular and Cellular Biochemistry : An International Journal for Chemical Biology in Health and Disease, 253(1-2), 307-312. doi:10.1 023/A:1026032404105

122. Gomez-Cabrera, M., Domenech, E., \& Viña, J. (2008). Moderate exercise is an a ntioxidant: Upregulation of antioxidant genes by training. Free Radical Biology an d Medicine, 44(2), 126-131. doi:10.1016/j.freeradbiomed.2007.02.001

123. Rajagopalan, S., Meng, X., Ramasamy, S., Harrison, D., \& Galis, Z. (1996). Reac tive oxygen species produced by macrophage-derived foam cells regulate the act ivity of vascular matrix metalloproteinases in vitro. implications for atherosclerotic plaque stability. The Journal of Clinical Investigation, 98(11), 2572-9.

124. Panday, A., Sahoo, M., Osorio, D., \& Batra, S. (2015). Nadph oxidases: An overv iew from structure to innate immunity-associated pathologies. Cellular \& Molecul ar Immunology, 12(1), 5-23. doi:10.1038/cmi.2014.89

125. Yamaguchi, M., Suzuki, G., Fuse, A., Yokota, H., Okamoto, K., Kusano, T., \& Ma tsuda, Y. (2015). The effects of xanthine oxidoreductase inhibitors on oxidative st ress markers following global brain ischemia reperfusion injury in c57bl/6 mice. $\mathrm{Pl}$ os One, 10(7). doi:10.1371/journal.pone.0133980

126. Xu, S., \& Touyz, R., Kidney Research Centre, Ottawa Health Research Institute, University of Ottawa, Ottawa, Ontario. (2006). Reactive oxygen species and vasc ular remodelling in hypertension: Still alive. Canadian Journal of Cardiology, 22(1 1), 947-951. doi:10.1016/S0828-282X(06)70314-2 
127. Xu, X., Hu, X., Lu, Z., Zhang, P., Zhao, L., Wessale, J., . . Chen, Y. (2008). Xant hine oxidase inhibition with febuxostat attenuates systolic overload-induced left v entricular hypertrophy and dysfunction in mice. Journal of Cardiac Failure, 14(9), 746-53. doi:10.1016/j.cardfail.2008.06.006

128. Brooks, S., DeVallance, E., D Audiffret, A., Frisbee, S., Tabone, L., Shrader, C., . .. Chantler, P. (2015). Metabolic syndrome impairs reactivity and wall mechanics of cerebral resistance arteries in obese zucker rats. American Journal of Physiolo gy, 309(6), 1846.

129. Malik, U., Hundley, N., Romero, G., Radi, R., Freeman, B., Tarpey, M., \& Kelley, E. (2011). Febuxostat inhibition of endothelial-bound xo: Implications for targeting vascular ros production. Free Radical Biology and Medicine, 51(1), 179-184. doi: 10.1016/j.freeradbiomed.2011.04.004

130. Marro, P. J., Baumgart, S., Delivoria-Papadopoulos, M., Zirin, S., Corcoran, L., McGaurn , S. P., ... Clancy, R. R. (1997). Purine metabolism and inhibition of xanthine oxidase in severely hypoxic neonates going onto extracorporeal membrane oxygenation. Pediatric Research, 41(4), 513-20. 